\title{
Especulaciones sobre una sorpresa: las elecciones en Nicaragua
}

Por nuestra experiencia sabemos que en este país solamente se puede quitar del gobierno al que administra mal, por la vía de las armas. ${ }^{1}$

Se trata de toda una excepción. Una ruptura completa con una tradición desgraciada. Por primera vez en nuestra historia los votos cambiarán gobierno. ${ }^{2}$

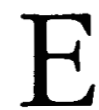

1 resultado de las elecciones del 25 de febrero de 1990 en Nicaragua influye en el modo en que se las analiza. Antes de los comicios, cuando todos los observadores y el gobierno de

${ }^{1}$ Declaraciones de un ex jefe contra al diario La Jornada, 7 de marzo de 1990, México.

${ }^{2}$ Luis Humberto Guzmán, "Elogio para sandinistas", La Cronica, núm. 67, 1 al 7 de marzo de 1990, Managua, p. 2.
Estados Unidos, anticipaban el triunfo del Frente Sandinista de Liberación Nacional (FSLN), los enfoques se centraban en los preparativos, en el margen de competitividad entre contendientes, la igualdad de los partidos en el acceso a los medios de comunicación, y cuestiones similares. Fuimos muy pocos los que nos preguntamos qué pasaría después. Ahora que las elecciones se llevaron a cabo y triunfó la principal opción opositora, los análisis se orientan a identificar las causas de la derrota del FSLN, dando por sentado que los comicios fueron honestos, puesto que perdió el candidato del gobierno. Las dudas que pudieron existir antes del 25 respecto dela pureza y transparencia del proceso 
electoral, se ven despejadas por la evidencia de los resultados. Es innegable que en todo esto existe una cierta coincidencia con la posición del gobierno de Estados Unidos: la mejor prueba de la limpieza de las elecciones es la derrota del FSLN, y más precisamente, la victoria de la Unión Nacional Opositora (UNO), la opción públicamente apoyada y financiada por la Casa Blanca y el Congreso estadunidense.

En este trabajo espero cumplir con tres objetivos. En primer lugar, presentar los aspectos centrales del proceso electoral, enmarcándolos en el proceso más amplio de democratización de Nicaragua y de pacificación regional, en un contexto de aguda crisis económica. En segundo lugar, adelantar algunas hipótesis para explicar el resultado de los comicios y la orientación mayoritaria del voto. Finalmente, plantear algunos desarrollos probables dentro de Nicaragua y en la región, a partir de la derrota electoral del FSLN.

El lector observará que a lo largo de todo el trabajo, y particularmente en la segunda parte, presto especial atención a los factores culturales y a las percepciones de la gente. Ello no implica desconocimiento de los factores estructurales, sino asumir que lo decisivo para entender los procesos políticos de masas es dilucidar el modo en que lo estructural se expresa en el nivel de la subjetividad, en las condiciones cotidianas de existencia de los individuos que componen los grupos, clases, géneros, etnias, etc. que dan vida a la sociedad: el modo en que la estructura deviene conciencia.

Las bases de las hipótesis en que este documento se apoya son, por supuesto, mis estudios y trabajos previos sobre Nicaragua, la observación del proceso electoral y, sobre todo, mi experiencia directa de diez años viviendo y tra- bajando en ese país. He reflexionado sobre la revolución sandinista y he escrito sobre ella, pero más importante que todo eso, la he vivido.

\section{EL PROCESO ELECTORAL Y SU CONTEXTO}

La convocatoria a elecciones generales en 1990 fue la segunda llevada a cabo por el régimen sandinista y está contemplada en la Constitución política, en vigor desde enero de 1987. Además de estar en juego en ellas la presidencia y la vicepresidencia de la república y las bancas de la Asamblea Nacional, por primera vez en la historia de Nicaragua se eligieron autoridades municipales y a los miembros de los nuevos Consejos Regionales en las recientemente creadasregiones autónomas de la Costa Atlántica. Las elecciones de febrero plantearon por lo tanto la posibilidad de una renovación total de las posiciones institucionales de autoridad. De conformidad con el texto constitucional, el mandato de los miembros de la Asamblea Nacional es de seis años, como los de presidente y vicepresidente.

Además del FSLN y la alianza electoral UNO compitieron ocho partidos políticos. Ellos son:

1) Partido Social Cristiano (PSC). La fórmula para presidente y vicepresidente estuvo integrada por Erick Ramírez y Rina Córdoba. El Partido Popular Social Cristiano, dirigido por Mauricio Díaz, abandonó la UNOa fines de 1989 y apoyó la boleta electoral del PSC, si bien uno de sus candidatos a diputado optó por permanecer en las listas de la UNO reteniendo su afiliación partidaria. Inicialmente el PSC contó con el apoyo de la organización indígena Yatama que en el último momento se sumó a la UNO en el plano nacional, y llevó sus propios can- 


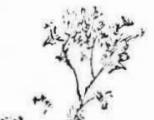

$7+y^{2}$

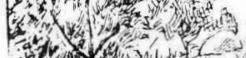
$4=0$

in

$y+\cdots$

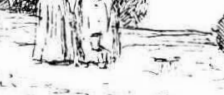


didatos para consejos regionales en las regiones autónomas Atlántico Norte y Atlántico Sur. ${ }^{3}$ Edén Pastora, el antiguo Comandante Cero de la insurrección sandinista, distanciado del FSLN desde 1981 y durante algún tiempo sumado a la contrarrevolución, también dio su apoyo al PSC, aunque sin participar en la contienda.

2) Partido Conservador Demócrata (PCD) (segundo lugar de votos en las elecciones de 1984); sus candidatos a presidente y vicepresidente fueron el actual diputado Eduardo Molina y Hugo Torres.

3) Partido Social Conservador (PSC) del viejo colaborador de Anastasio Somoza, Fernando Agüero, quien regresó a Nicaragua después de un exilio de casi diez años en Miami; la negativa de la UNO de aceptarlo en sus filas lo llevó a inscribir este pequeño partido que lo postuló como candidato presidencial.

4) Partido Liberal Independiente de Unidad Nacional (PLIUN), una reciente escisión del Partido Liberal Independiente (PLi); postuló a Rodolfo Robelo y Lombardo Martínez.

5) Movimiento de Acción Popular Marxista Leninista (MAP). Presentó a Isidro Téllez como candidato a presidente y a su actual diputado Carlos Cuadra como candidato a vicepresidente.

6) Partido Revolucionario de los Trabajadores (PRT), de izquierda revolucionaria: Bonifacio Miranda y Juan Carlos Leyton fueron sus candidatos.

7) Movimiento de Unidad Revolucionaria (MUR), postuló como candidato a presidente a Moisés Hassán, integrante de la primera Junta de Gobierno de Reconstrucción Nacional y hasta 1988 alcalde de Managua. El MUR es ante todo

${ }^{3}$ La Prensa, 9 de febrero de 1990. un partido de disidentes del FSLN, centró su campaña electoral en las denuncias a la corrupción administrativa y se autodefine de izquierda democrática.

8) Partido Unionista Centroamericano (PUCA) postuló como candidata a presidente a la escritora Blanca Rojas.

El MUR, el PLIUN, el PRT, el PUCA y el PSCO, participaron por primera vez en elecciones.

El FSLN postuló la reelección del presidente comandante Daniel Ortega y el vicepresidente Sergio Ramírez. Optó por una campaña electoral al estilo norteamericano: bullanguera, con gran despliegue de recursos materiales, regalos, música, bailes y reinas de belleza; el candidato presidencial se despojó de sus anteojos y su uniforme verde olivo, optó por una apariencia juvenil y festiva -popularmente denominada Danny look-y se involucró públicamente en los ritos del catolicismo-asistencia a misas, referencias "al Señor" en sus discursos. Se adoptó una consigna triunfalista: "Todo será mejor" y un programa en el que se anticipaba la solución de todos los problemas del país sobre la base del acceso a fondos externos que estarían disponibles a partir de la victoria electoral y la desmovilización de la contra. Esta línea de propaganda se articuló con otra que se refería al candidato presidencial como "el gallo ennavajado", apelando a claras resonancias de la cultura popular (las riñas de gallos) y la simbología machista de superioridad frente a la mujer candidata presidencial de la UNO.

El eje de la propaganda electoral del FSLN fue la identificación de la UNO con la contrarrevolución y la ex Guardia Nacional del dictador Somoza, merced a la existencia de varios candidatos de la UNO con un claro pasado de funcionarios somocistas, y asesores de su candidata presidencial con reciente vincula- 
ción a la Resistencia Nacional -su hijo Pedro Joaquín Chamorro Barrios; Alfredo César, su más prominente asesor; ${ }^{4}$ también un número de candidatos a cargos municipales en algunos departamentos tenían un pasado reciente de miembros o colaboradores de la contra- Asimismo los candidatos del FSLN acentuaron en sus discursos y proclamas los mensajes dirigidos a la empresa privada con el claro fin de captar sus votos. Se anticipó la revisión de las afectaciones de tierras de la reforma agraria y se ofrecieron garantías renovadas a la propiedad privada y a la inversión extranjera. ${ }^{5}$ El indulto acordado a último momento a los condenados por crímenes cometidos contra la población durante la guerra contrarrevolucionaria, y a 39 ex oficiales de la Guardia Nacional condenados por actos genocidas, se inscribe también en esta política de competir con la UNO por los votos de la derecha, y de mejorar la imagen exterior del FSLN

${ }^{4}$ Sin embargo debe señalarse que al mismo tiempo muchos de los nombres más prominentes de la UNO estuvieron en el pasado vinculados al sandinismo: Virgilio Godoy fue ministro del Trabajo desde 1979 hasta principios de 1984, doña Violeta integró la primer Junta de Gobierno de Reconstrucción Nacional, y Alfredo César fue presidente del Banco Central entre 1980 y 1982.

5 Declaraciones de Daniel Ortega en Barricada, 14 de diciembre de 1989, Managua, y de Sergio Ramírez en La Jornada, 24 de febrero de 1990. Las referencias a las nacionalizaciones de la etapa revolucionaria inicial desaparecieron de los medios de comunicación sandinistas inclusoen las efemérides. Por ejemplo, al informar sobre el acto de conmemoración del décimo aniversario de la nacionalización del comercio exterior, el diario Barricada, órgano oficial del FsLN, se refirió al "décimo aniversario de la nacionalización de algunos productos exportables" (18 de diciembre de 1989, p. 4), aunque después de la derrota electoral del 25 de febrero la nacionalización del comercio exterior volvió a figurar como uno de los logros revolucionarios del sandinismo, Barricada, 28 de febrero de 1990, p. 1. ante una victoria que parecia incuestionable.

La UNO por su lado lucía como una frágil coalición de inicialmente catorce y luego trece partidos políticos: Partido Liberal Independiente (PLI) que fue la tercera fuerza en las elecciones de 1984, Partido Liberal Constitucionalista (PLC), Partido Neo Liberal (PALI), Partido Nacional Conservador (PNC), Alianza Popular Conservadora (APC), Acción Nacional Conservadora (ANC), Partido Democrático de Confianza Nacional (PDCN), Partido de Acción Nacional (PAN), Partido Socialista Nicaragüense (PSN), Partido Social Demócrata (PSD), Movimiento Democrático Nicaragüense (MDN), Partido Comunista de Nicaragua (PC de N) y Partido Integracionista de América Central (PIAC). La fórmula presidencial estuvo integrada por Violeta Barrios de Chamorro, viuda del periodista Pedro Joaquín Chamorro asesinado en enero de 1978 por la dictadura somocista, y Virgilio Godoy, presidente del PLI y ex ministro de Trabajo del gobierno sandinista hasta marzo de 1984. La elección de Godoy a la candidatura vicepresidencial costó muchos esfuerzos dentro de la UNO dada la insistencia de los agrupamientos conservadores en designar al empresario Alejandro Bolaños, un virulento opositor al sandinismo con fuerte apoyo de la comunidad de negocios.

La UNO no ocultó la presencia de ex somocistas en sus listas, y tampoco trató de disimular su condición de opción respaldada por Washington; la hipótesis de sus dirigentes fue que lo primero no era relevante para la población $-y$ en algunas zonas podia ser, por el contrario, un elemento positivo-, y que lo segundo. era en realidad un activo. El núcleo de la campaña de la UNO consistió en responsabilizar al gobierno sandinista del descalabro económico a causa de 


\section{1}

sus enfoques "comunistas", la corrupción administrativa y los gastos militares que considera excesivos. Prometió poner fin a la guerra y eliminar inmediatamente el servicio militar; sus propuestas económicas fueron relativamente moderadas y generalmente vagas -si se exceptúan los exabruptos de algunos asesores-, particularmente en lo referente a la cuestión de la reforma agraria y las propiedades confiscadas o expropiadas por el régimen sandinista. Promocionó ante todo la figura de su candidata a presidente, asociándola a imágenes maternas y de la religiosidad popular. ${ }^{6}$

${ }^{6}$ Hay el agudo análisis de la simbología de la campaña electoral del FSLN y la uNo, en Oscar R. Vargas, "Misticismo y tradición durante la campaña electoral", La Crónica, núm. 70, 22 a 28 de marzo de 1990, pp. 10-11.
El apoyo político y económico del gobierno de Estados Unidos a la UNO fue público y constituyó para ésta un motivo de abierto orgullo. Del mismo modo la fuente principal de financiamiento de la campaña de la UNO fue una partida de entre 5 y 9000000 de dólares, aprobada por el Congreso norteamericano a solicitud de la Casa Blanca. Debido a las demoras burocráticas del gobierno sandinista y a la propia impericia de la UNO en la elaboración de proyectos y en el montaje legal de las instituciones que debían canalizarlo internamente, el financiamiento comenzó a llegar tardíamente, a principios de 1990 , cuando la campaña ya estaba bien iniciada.

No menos importante ha sido para la unOel apoyo obtenido de la jerarquía de la Iglesia católica y en primer lugar del

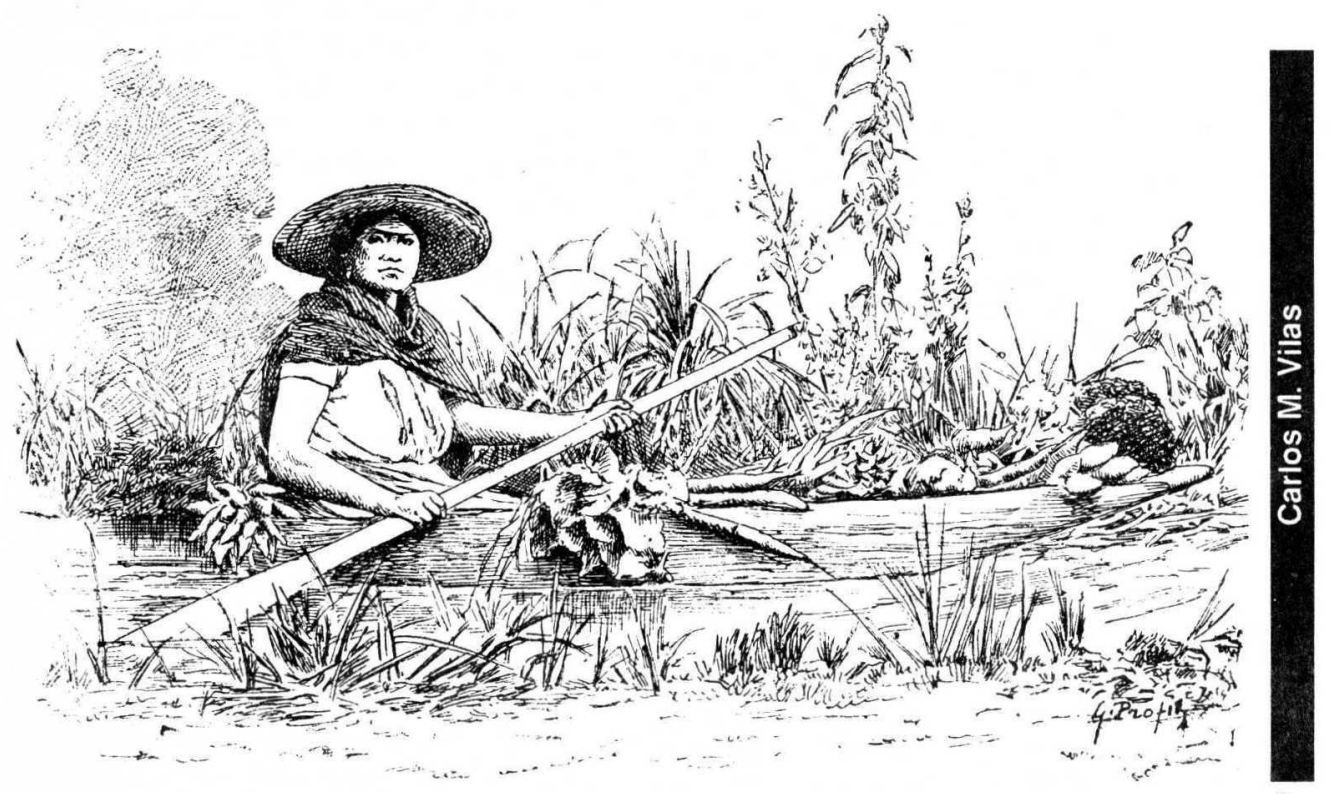


cardenal Miguel Obando y Bravo. Si para muchos nicaragüenses las excelentes relaciones con la Casa Blanca significaban que la UNOse ubicaba del lado de los poderosos, la larga oposición de monseñor Obando al régimen sandinista, la prolongada y virulenta historia de enfrentamientos, y finalmente sus simpatías abiertas por doña Violeta, ofrecían una legitimación espiritual a la opción opositora mucho más convincente que las públicas simpatias de las comunidades de base o la teología de la liberación por el sandinismo. Fotos del cardenal impartiendo su bendición a doña Violeta de Chamorro fueron profusamente difundidas a través del diario La Prensa-del que doña Violeta es directora-, indicando sin ambigüedades hacia dónde se encaminaban las preferencias del prelado.

La nutrida lista de opciones electorales estuvo abierta a 1752088 nicaragüenses, de los que más de la mitad es menor de 25 años, y alrededor de $35 \%$ votó por primera vez. El proceso electoral fue seguido por algo más de 1000 observadores internacionales. Las misiones más nutridas fueron las de la ONU y la OEA, que comenzaron a instalarse en septiembre de 1989 para cubrir el proceso de inscripción que se efectuó durante cuatro domingos de octubre. Otras misiones de observación corresponden al Consejo de Jefes de Gobierno Libremente Electos, del ex presidente James Carter, Center for Democracy (EU), Hemispheric Initiatives (EU), Latin American Studies Association, etcétera.

Los informes emitidos periódicamente por las misiones de observación coincidieron en señalar el desenvolvimiento, en general correcto, de la campaña. Las denuncias formuladas por el gobierno de Estados Unidos y por algunos voceros de la UNO, en el sentido de que el gobierno sandinista prepararía un "in- menso fraude", o no reconocería los resultados del escrutinio, no fueron acompañados por evidencia alguna y fueron descartadas por los observadores; el día previo a los comicios el secretario general de la OEA, que se encontraba presente presidiendo la misión de observación de su organización, declaró a la prensa que la posibilidad de un fraude debía ser rechazada. Por su parte, el FSLN denunció en varias oportunidades que la UNO se retiraría de los comicios a último momento para deslegitimarlos, algo que la uNo desmintió sistemáticamente. Los incidentes de violencia durante la campaña fueron esporádicos.

Una de las innovaciones en la legislación electoral nicaragüense fue la posibilidad de financiamiento externo a los partidos, con la única condición de que $50 \%$ de la ayuda fuera entregada al Consejo Supremo Electoral -que constituiría un fondo para la democracia- que a su vez distribuiría parte del mismo a los restantes partidos políticos. Un tema álgido en la campaña electoral fue el ofrecimiento de fondos a la UNO por el gobierno de Estados Unidos. El monto total percibido por la coalición opositora es aún difícil de calcular con exactitud, lo mismo que las sumas recibidas por el FSLN. Las estimaciones del apoyo financiero externo al sandinismo sugieren en todo caso sumas más reducidas y no alcanzan al millón de dólares. Una parte de este financiamento fue entregado en especie, lo que permitió al FSLN evitar la obligación legal de entregar 50\% al Consejo Supremo Electoral, al mismo tiempo que conducir una vistosa y colorida campaña electoral colmada de obsequios a los empleados públicos y sus familias, pobladores de barrios populares, asistentes a las concentraciones, etcétera?

\footnotetext{
${ }^{7}$ Sobre el financiamiento norteamericano a la
}

1

2

5 


\section{LA DEMOCRATIZACION DE NICARAGUA}

Las elecciones del 25 de febrero constituyen, ante todo, un importante momento en el proceso de democratización en Nicaragua. Este proceso no se inició con la convocatoria electoral ni se reduce a ella. Se remonta, ante todo, al triunfo revolucionario de julio 1979 , al desmantelamiento de la dictadura somocista y al establecimiento de amplios canales de participación popular y acceso a recursossocioeconómicos-educación, salud, empleo estable, medios de producción y crédito, etc.-quebeneficiaron a sectores muy amplios de la población. El énfasis inicial en la dimensión socioeconómica de la participación y la democratización fue complementado posteriormente con la ampliación de la vida política y las elecciones generales de noviembre 1984 , convocadas y celebradas en momentos en que la guerra contrarrevolucionaria, apoyada abiertamente por el gobierno de Estados Unidos, iniciaba su etapa de mayor intensidad.

En esas elecciones el FSLN obtuvo una amplia mayoría $(67 \%$ de los votos válidos), y un tercio del electorado decidió abstenerse, o no pudo ejercer el voto

UNO, "International Comission of the Latin American Studies Association to Observe the February 25, 1990 Nicaraguan Election. Interim Report, December 15, $1989^{n}$, en LASA Forum XXX(4), Winter 1990, pp. 33-44, y Excélsior, 22 de febrero de 1990; sobre el financiamiento al FSLN, el reportaje al comandante Bayardo Arce en La Crónica, núm. 64,8 a 14 de febrero de 1990 . Las denuncias de la uNode que el Partido Revolucionario Institucional (PRI) gobernante en México entregó 11000000 de dólares para la campaña del fsun al margen de la legislación electoral, fueron desmentidas, La Jornada, 11 de marzo de 1990 . Por su lado fuentes de Estados Unidos han estimado en 26000000 de dólares la ayuda brindada por el gobierno norteamericano a la oposición nicaragüense - no exclusivamente a la UNO- desde principios de 1989, La Jomada, 12 de marzo de 1990. por encontrarse en zonas rurales donde las fuerzas contrarrevolucionarias hacian imposible la concurrencia a las umas. El principal grupo opositor, la Coordinadora Democrática Nicaragüense $(\mathrm{CDN})$-de abiertas vinculaciones con los grupos contrarrevolucionarios-decidió abstenerse, con el fin de reducir la legitimidad de la convocatoria y salvar a sus candidatos del desprestigio de una derrota casi segura. ${ }^{8} \mathrm{El}$ retiro de la organización más claramente identificada con la política antisandinista de Washington se convirtió en el argumento central del gobierno de Ronald Reagan y sus aliados internacionales para desconocer la legalidad y honestidad de los comicios, pese a la participación de otras seis organizaciones.

La posición de Estados Unidos fue asumida con algunos matices por varios dirigentes y gobiernos de América Latina, y de Europa, que por lo menos contribuyeron a difundirla imagen, hoy fuertemente arraigada en la opinión pública internacional, que en todo caso las elecciones de 1984 no habían sido del todo buenas. Ello a pesar de los dictámenes de las misiones de observación del Parlamento británico, el gobierno de Holanda, el Parlamento irlandés, la Internacional Socialista, la Latin American Studies Association, y otras, que coincidieron en el carácter limpio, competitivo y honesto del proceso electoral. ${ }^{9}$

${ }^{8}$ En entrevistas concedidas en esa época al autor por Clemente Guido, candidato presidencial del PCDen esas elecciones, y or Luis Humberto Guzmán, candidato a miembro de la Asamblea Nacional por el Partido Popular Socialcristiano, se mencionó que la abstención de la Coordinadora Democrática obedeció a presiones del gobierno de Estados Unidos.

${ }^{9} \mathrm{Vid}$. por ejemplo The electoral process in Nicaragua: domestic and intemational influences, The Report of the Latin American Studies Association Delegation to observe the Nicaraguan General Election of november 4, 1984. LASA, 19 de noviembre de1984. 


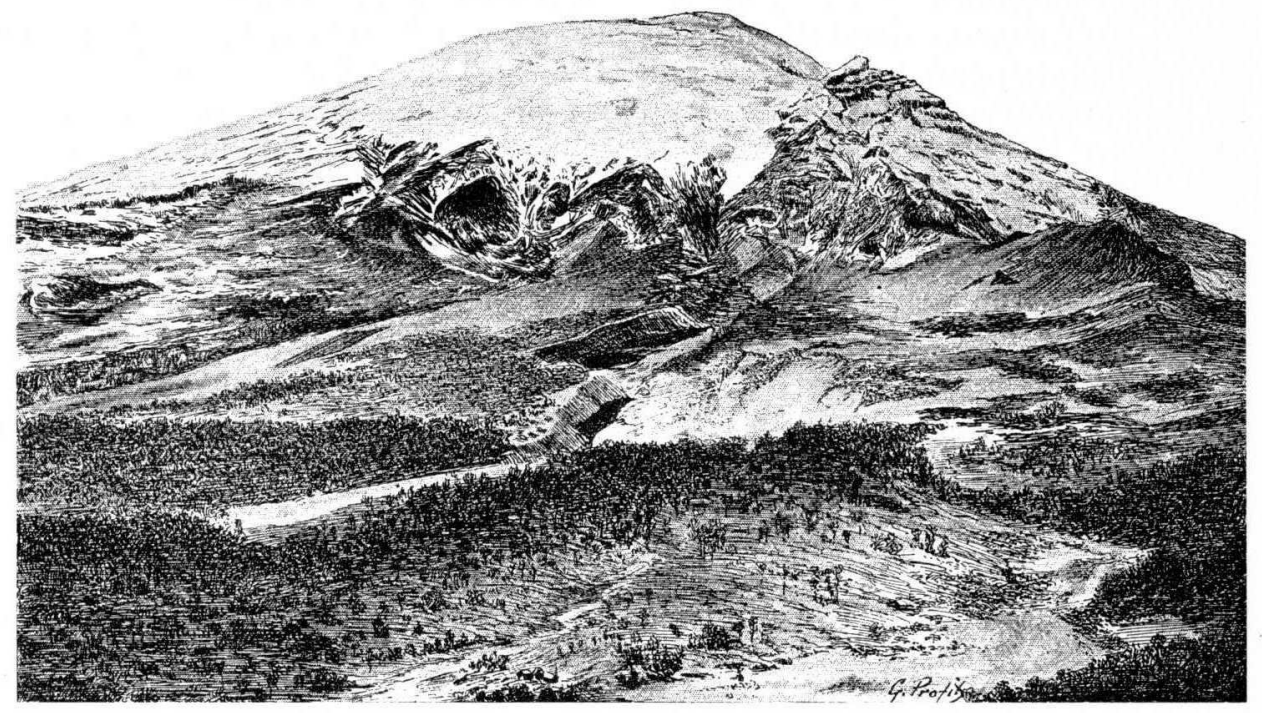

En enero de 1987 entró en vigencia una nueva constitución política después de un proceso de casi dos años de amplias discusiones y consultas a lo largo y lo a ancho del país que introdujeron numerosas modificaciones en el proyecto original, y en septiembre de 1988 se aprobó la ley de autonomía regional de los grupos étnicos de la Costa Atlántica. En octubre del mismo año se modificó la ley de partidos políticos, acogiéndose muchas de las iniciativas de reforma de los partidos opositores. En febrero de 1989 el gobierno decidió anticipar la fecha de las elecciones de noviembre de 1990 a febrero de ese mismo año. En abril de 1989 la Asamblea Nacional aprobó una nueva ley electoral, que amplió las garantías de competitividad, acceso igualitario a los medios de comunicación para todos los partidos participantes, aceptación de financiamiento externo, respeto a las autoridades electo- rales, invitación a misiones de observación internacional. La misma Asamblea aprobó una nueva ley de medios de comunicación social, ampliando las garantías de acceso a los medios para los partidos de oposición. En agosto de 1989 se aceptó la moción de los partidos opositores de adelantar a abril de $1990 \mathrm{el}$ inicio del periodo de gobierno de las autoridades surgidas de las elecciones de febrero. En esta misma ocasión los partidos de la oposición suscribieron con el FSLN una declaración reclamando la completa desmovilización de los grupos contrarrevolucionarios.

LAS ELECCIONES DE FEBRERO Y LA CRISIS REGIONAL

Desde la perspectiva del sandinismo la ampliación del espacio institucional para la actividad política opositora fue con- 
siderada una contribución a la desmovilización de la contra, el desmantelamiento de los campamentos ubicados en Honduras, el cese del apoyo económico del gobierno de Estados Unidos, y la terminación definitiva del conflicto; las fuerzas contrarrevolucionarias se encuentran militarmente derrotadas, aunque el costo de ello, para Nicaragua, fue de decenas de miles de víctimas y el descalabro de la economía. Pero, al mismo tiempo, mucha gente consideró que la ampliación del espacio político para sus actores tradicionales era una resultante de las presiones de los contras y el gobierno de Estados Unidos, más que mérito sandinista o prueba de su vocación democrática. Finalmente, las reformas políticas pueden ser interpretadas también como un resultado del creciente involucramiento del proceso político doméstico en la crisis regional y en los mecanismos diseñados para solucionarla, y la participación de la comunidad internacional en el desenvolvimiento de los procesos políticos regionales.

En agosto de 1987 los presidentes centroamericanos firmaron el acuerdo regional de paz conocido como Esquipulas II que, además de demandar el cese del apoyo extrarregional a los grupos de oposición armada (en el caso de Nicaragua, cese del financiamiento y entrenamiento de Estados Unidos a la contra), obligaba a cada signatario a la libertad de los detenidos políticos, levantamiento del estado de sitio, pleno restablecimiento de los derechos civiles y políticos, establecimiento de diálogo con todos los grupos políticos de oposición, y el convocar a procesos electorales de acuerdo con las disposiciones de los respectivos textos constitucionales. El gobierno de Nicaragua, en ejecución de esos acuerdos, creó una Comisión Nacional de Reconciliación con participación amplia de los partidos opositores, encargada de supervisar el cumplimiento de los acuerdos y designó como su presidente al cardenal Miguel Obando y Bravo, uno de sus más acerbos críticos. El gobierno de Nicaragua abandonó asimismo su negativa a negociar directamente con la contrarrevolución; en marzo de 1988 firmó con la dirigencia de la Resistencia Nicaragüense (RN) un acuerdo provisorio de cese al fuego que, aún después que las conversaciones fueron unilateralmente interrumpidas por la $\mathrm{RN}$, fue renovado también unilateralmente por el gobierno sandinista por sucesivos periodos de 30 días hasta fines de 1989.

En la reunión de Costa del Sol en El Salvador (febrero de 1989) los cinco presidentes acordaron un plan de desmovilización de la contrarrevolución que debía culminar el 5 de diciembre de 1989. En esa oportunidad el presidente Ortega anunció el adelantamiento de la fecha de las elecciones, y el indulto a aproximadamente 1200 ex guardias somocistas condenados por los tribunales por su involucramiento en crimenes contra la población civil. En la reunión de presidentes centroamericanos celebrada en Tela (7 de agosto de 1989) los cinco presidentes acordaron un proceso de desmovilización de la contra supervisado por la ONU que debía completarse al 5 de diciembre, fecha de inicio de la campaña electoral. Como se sabe, la desmovilización no tuvo lugar. Poco después, en la reunión de presidentes en San Isidro Coronado (Costa Rica) en diciembre del mismo año, Daniel Ortega se sumó al pleno respaldo de sus colegas al presidente salvadoreño Alfredo Cristiani y a la condena al FMLN y su ofensiva militar; como contrapartida obtuvo de los demás presidentes el reclamo para que la contra concluyera el proceso de desmovilización a más tardar el 5 de 
febrero de 1990. Este reclamo tampoco obtuvo eco ni de los contrarrevolucionarios ni del gobierno de Estados Unidos.

\section{EL CONTEXTO SOCIOECONÓMICO DE LAS ELECCIONES}

El escenario económico de las elecciones de febrero fue el peor de la historia y se convirtió obviamente en el tema central del debate electoral. En el último trienio el PIB acumuló una caída de $11.7 \%$ y el per cápita cayó $21.5 \%$; la balanza comercial acumuló saldos negativos por 1.2 mil millones de dólares y la balanza de cuenta corriente por -2 millones; en 1989 la deuda externa sumó 7579 millones, equivalente a 2300 por habitante. La escasez de divisas frescas es dramática, y las apelaciones del gobierno sandinista a la comunidad internacional han producido, hasta el momento, resultados magros.

Un drástico programa de ajuste que la CEPAL calificó de "draconiano" ${ }^{10}$ redujo en 1989 las brechas externas, la hiperinflación (de más de $33000 \%$ en 1988 a algo menos de $1700 \%$ en 1989) y el déficit fiscal (de 25\% del PIB en 1988 a casi 5\% en 1989), y reactivó ligeramente las exportaciones. Los costos incluyen una fuerte retracción productiva, falta de liquidez, deterioro adicional de los servicios sociales, caída del consumo y casi 35\% de desempleo y subempleo. La contracción del consumo, el endeudamiento del campesinado, y la caída vertical de los salarios, efectos normales de este tipo de estrategias, tuvieron lugar en un marco que ya se caracterizaba desde años atrás por una evolución de la eco-

10 Vid. CEPAL, Balance económico preliminar de la economía latinoamericana, diciembre de 1989. nomía negativa para las clases populares. El nivel del salario real cayó de un índice de 29.2 en febrero de 1988 (con relación a $1980=100$ ) a un índice de 6.5 en junio de 1989 y a 1 en diciembre del mismo año. Durante 1988 el consumo de leche se redujo casi $50 \%$, y el consumo de azúcar, que durante 1988 fue de un promedio mensual de 200000 quintales, cayó a principios de 1989 a 124000 quintales; enfermedades como la tuberculosis y la malaria se extendieron de manera notoria, y durante el primer trimestre de 1989 la mortalidad infantil por diarrea duplicó la de similar periodo de 1988. ${ }^{11}$

La economía de Nicaragua se encuentra en muy precarias condiciones como resultado de casi una década de guerra contrarrevolucionaria impulsada por el gobierno de Estados Unidos y cinco años de embargo comercial, pero también por el propio efecto de las transformaciones socioeconómicas y no pocos desaciertos de política económica -aunque no tanto por lo que toca a su formulación global, o macroeconómica, como por sus efectos en la vida cotidiana de la gente, en el desenvolvimiento de las unidades de producción, etc. Todos estos aspectos han sido suficientemente ilustrados en numerosos trabajos y a ellos me remito. ${ }^{12}$

${ }^{11}$ Barricada, 15 y 21 de febrero de 1989; $E l$ Nuevo Diario, 27 de abril de 1989, Managua. Según estimaciones de funcionarios del Ministerio de Educación la tasa de analfabetismo en la región III (Managua) era $30 \%$ de la población adulta a fines de 1988. Al mismo tiempo los becarios que regresan del exterior después de cinco y seis años de estudios universitarios, no encuentran empleo a causa de la contracción del aparato productivo y de los servicios, Barricada, 20 y 21 de febrero de 1989.

${ }^{12}$ Véase por ejemplo Carlos M. Vilas, Transición desde el subdesarrollo, Ediciones Nueva 


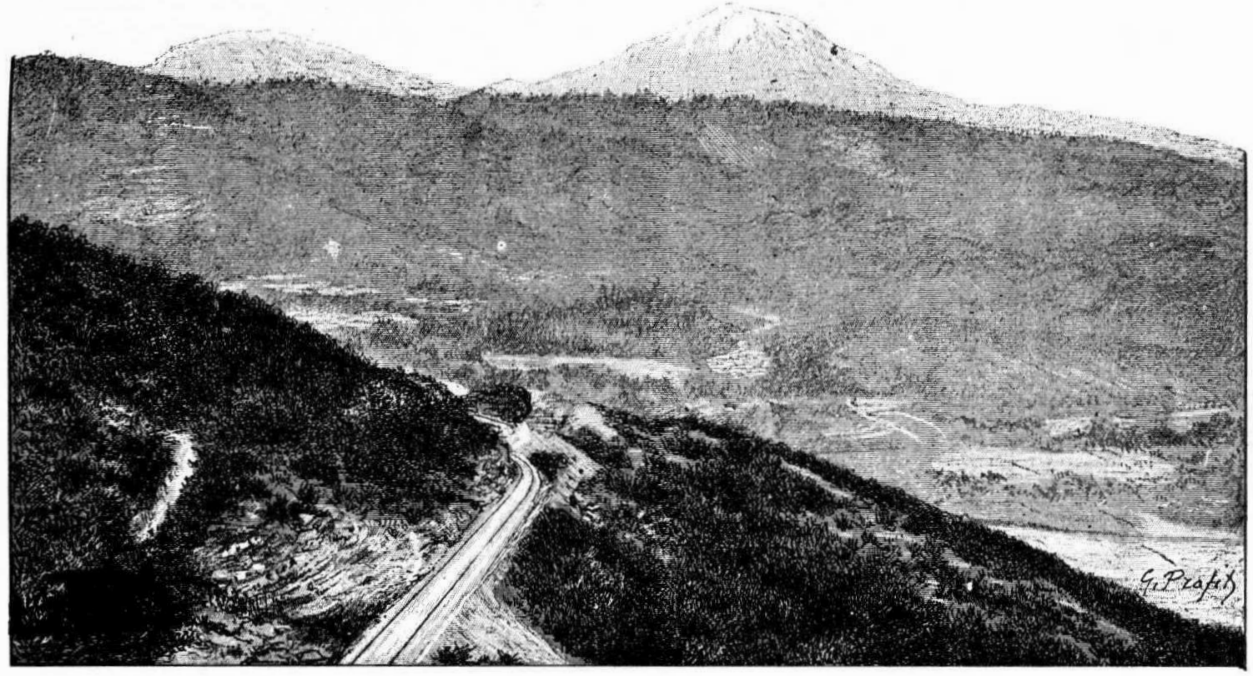

A su vez guerra y crisis enmarcaron una desaceleración del proceso de transformaciones revolucionarias y la reversión de algunas de sus medidas iniciales de mayor impacto popular. La estrategia adoptada por el régimen sandinista para enfrentar la agresión externa consistió en una política de concesiones económicas amplias a los grupos de burguesía agraria, y de contención de las demandas obreras y campesinas con el fin de mantener unido el frente político nacional ante la guerra contrarrevolucionaria y el gobierno de Estados Unidos. ${ }^{13}$ En

Sociedad, Caracas, 1989 ; Rose Spalding (comp.), The political economy of revolutionary Nicaragua, Allen \& Unwin, Boston, 1987, etcétera.

${ }^{13}$ La ilustración más reciente de esta estrategia de distribución desigual de beneficios y sacrificios se encuentra en la asamblea del Ministerio de la Reforma Agraria (MIDINRA) con empresarios, campesinos y obreros del campo en el marco de la consecuencia el nivel de movilización popular se redujo y la autonomía relativa de las organizaciones populares disminuyó ante su creciente desempeño como aparatos del estado y su subordinación al FSLN, a medida que la crisis creciente de la economía determinaba que las políticas de subsidio a los sectores me-

denominada política de concertación ( 20 de abril de 1989), en la cual el gobierno aprobó un subsidio de 1000000 de córdobas por manzana a los algodoneros -que en verdad no habían solicitado- y rechazó la demanda obrera de un salario que cubriera como mínimo una canasta de ocho productos básicos. Para otros ejemplos y una discusión de estos aspectos de la revolución, Carlos M. Vilas, "Unidad nacional y contradicciones sociales en una economía mixta: Nicaragua 1979-1984", en Richard Harris y Carlos M. Vilas (comps.), La revolución en Nicaragua: liberación nacional, democracia popular y transformación económica, Ediciones Era, México, 1985, pp.1750, y Transición..., op. cit., caps. III y IV. 


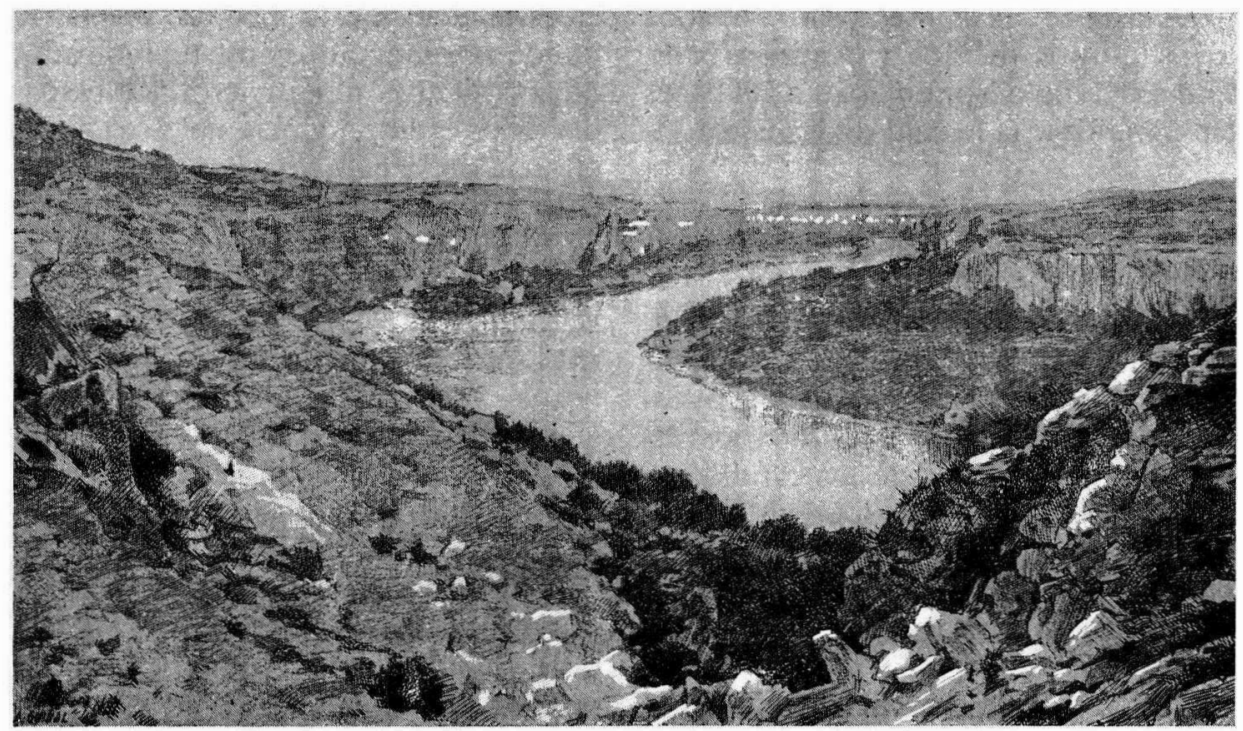

dios y empresariales se financiaran de más en más con la reducción del consumo, los ingresos y las condiciones de vida de las fuerzas motrices de la revolución. ${ }^{14}$

14 La adopción de decisiones orientadas a controlar la activación y las demandas populares cuando ellas amenazan con independizarse de la conducción del estado, y la paulatina disminución de los niveles de movilización social, han sido señaladas y analizadas desde hace varios años, por ejemplo: Carlos M. Vilas, Perfiles de la revolución sandinista, Editorial Legasa/Casa de las Américas, Buenos Aires/La Habana, 1984, caps. IV y v; Marvin Ortega, "Worker's participation in the management of the agro-enterprises of the APP", Latin American Perspectives, núm. 45, primavera de 1985 , pp. 69-81; C.M. Vilas, "The mass organizations in Nicaragua: the current problematic and perspectives for the future", Montbly Review, núm. 38 , noviembre de 1986 , pp. 20-31; y más recientemente Luis Serra, "Limitada por la guerra; pendiente a futuro: la participación y organización popular en Nicaragua", Nueva Sociedad, núm 104,
La incapacidad de la revolución sandinista de avanzar por encima de los límites de su etapa inicial, apoyada en una amplia alianza de grupos y clases sociales, dio mayor visibilidad a sus limitaciones, a los compromisos celebra-

noviembre-diciembre de 1989, pp. 134-143. Debe reconocerse sin embargo que la mención de este tipo de hechos solía acarrear reacciones agresivas de quienes preferían ver todo color de rosa e interpretaban cualquier señalamiento crítico casi como una traición a la revolución, por ejemplo: William I. Robinson y Ken Norsworthy, "Comment on Vilas", Montbly Review, núm. 38, diciembre de 1986, pp. 44-47. Algunas encuestas preelectorales efectuadas a fines de 1989 revelaron un mayor deterioro de la participación popular. La que llevó a cabo el Instituto Nicaragüense de Opinión Pública (INOP) en Managua en octubre de ese año indicó, por ejemplo, que dos tercios de los encuestados (en su mayoría habitantes de barrios populares) no participaba en actividades de desarrollo comunal (higiene ambiental, vacunaciones, huertos comunales y similares). 
dos hacia la derecha y con la comunidad internacional, al fortalecimiento de los estilos políticos tradicionales, al peso creciente en las decisiones del gobierno y del FSLN de sus elementos más ligados a los grupos medios y empresariales, que sin duda desorientaban a las bases sin garantizar la lealtad de las elites.

\section{¿POR QUE LA GENTE VOTÓ COMO VOTÓ?}

El resultado de las elecciones del domingo 25 de febrero sorprendió a la totalidad de los observadores y, por supuesto, al sandinismo y sus partidarios. Es posible que muchos de los candidatos de la UNO tampoco hayan previsto el resultado: no tanto en el sentido del voto, como en su magnitud..$^{15}$ Doña Violeta se apuntó un triunfo indiscutible en las elecciones más limpias y competitivas jamás habidas en el hemisferio occidental, y por añadidura convocadas por un gobierno cuyo candidato resultó vencido. El voto del 25 también fue una sorpresa para el gobierno norteamericano, que en los días finales de la campaña venía intentando hacerse a la idea de una victoria sandinista, y a una relativa reconciliación con Managua. Nunca el presidente George Bush esperó ganar tanto: lo que Ronald Reagan no pudo conseguir con los contras y el descalabro de la economía, Bush lo obtuvo con los votos de más de la mitad de los nicaragüenses, aunque en un terreno estratégicamente abonado por su antecesor.

${ }^{15}$ Hay que reconocer sin embargo la relativamente buena aproximación de lo que entonces pareció un exabrupto y ahora anticipación de Virgilio Godoy: "...las 300000 o 400000 personas que acudieron ayer a la plaza son los votos que sacarán los sandinistas el próximo domingo", La Jornada, 25 de febrero de 1990.
La participación electoral fue más alta de lo esperado; votó $87.5 \%$ de los ciudadanos inscritos, con una abstención de sólo $12.5 \%$, menor que la de las recientes. elecciones en Costa Rica (20.2\%). Esto puede ser entendido como un indicador de la confianza que tuvieron los ciudadanos en la importancia del acto, en la eficacia de la participación y en el respeto a los resultados. ${ }^{16} \mathrm{La}$ UNO recibió $54.7 \%$ de los votos válidos emitidos, el FSLN 40.8\%, y el resto se distribuyó entre las otras ocho opciones, de las que el MUR surge como tercera -si bien muy lejana- fuerza, con $1.1 \%$ de los votos, seguido por el PSC con $0.7 \%$. Doña Violeta de Chamorro obtuvo 777552 sufragios, y Daniel Ortega 579 996. La UNO se ha asegurado 51 bancas en la Asamblea Nacional, el FSLN 39, y el MUR y el PSC una cada uno (cuadro 1).

En la boleta para elegir presidente $y$ vicepresidente, la fórmula Violeta Chamorro de Barrios-Virgilio Godoy de la UNO ganó en siete de las nueve regiones electorales, y la fórmula Daniel Ortega Saavedra-Sergio Ramírez, del FSLN, en sólo dos (región I correspondiente a los departamentos de Estelí, Madriz y Nueva Segovia, y región IX correspondiente a Río San Juan). Pero en la región I la victoria fue por sólo 300 votos sobre un total de casi 140000 . En la boleta de representantes ante la Asamblea Nacional el FSLN triunfó también en estas dos regiones, y en una tercera (región autónoma Atlántico Norte) la repartición de votos con el Partido Social Cristiano y la UNO sólo le permitió obtener un representante.

De las 17 cabeceras departamentales la UNO se adjudicó once (Managua, Chinandega, Boaco, Chontales, Jinotega, Ma-

\footnotetext{
${ }^{16}$ Se registraron menos de $6 \%$ de votos inválidos.
} 
Cuadro 1

RESULTADOS DE LAS ELECCIONES DEL 25 DE FEBRERO DE 1990, POR REGIÓN

\begin{tabular}{|c|c|c|c|c|c|}
\hline Regiones* & & UNO & $F S L N$ & Otros & Total \\
\hline \multirow[t]{2}{*}{ I } & Votos $^{2}$ & 66661 & 66960 & 6053 & 139674 \\
\hline & $\mathrm{AN}^{\mathrm{b}}$ & 4 & 5 & - & 9 \\
\hline \multirow[t]{2}{*}{ II } & Votos $^{2}$ & 126386 & 105357 & 9292 & 241035 \\
\hline & $\mathrm{AN}^{\mathrm{b}}$ & 8 & 7 & - & 15 \\
\hline \multirow[t]{2}{*}{ III } & Votos $^{2}$ & 209527 & 168061 & 13830 & 391418 \\
\hline & $A N^{b}$ & 14 & 11 & - & 25 \\
\hline \multirow[t]{2}{*}{ IV } & Votos ${ }^{2}$ & 135117 & 110090 & 8824 & 254031 \\
\hline & $A N^{b}$ & 8 & 6 & - & 14 \\
\hline \multirow[t]{2}{*}{$\mathrm{v}$} & Votos ${ }^{2}$ & 97911 & 35081 & 6495 & 139487 \\
\hline & $\mathrm{AN}^{\mathrm{b}}$ & 8 & 6 & - & 10 \\
\hline \multirow[t]{2}{*}{ vi } & Votos $^{2}$ & 105020 & 65499 & 11025 & 181544 \\
\hline & $A N^{b}$ & 7 & 4 & - & 11 \\
\hline \multirow[t]{2}{*}{ VII } & Votos $^{2}$ & 19253 & 15044 & 5648 & 39945 \\
\hline & $A N^{b}$ & 1 & 1 & $1^{c}$ & 3 \\
\hline \multirow[t]{2}{*}{ VIII } & Votos ${ }^{2}$ & 13040 & 7256 & 1185 & 21481 \\
\hline & $A N^{b}$ & 1 & 1 & - & 2 \\
\hline \multirow[t]{2}{*}{$\mathrm{Ix}$} & Votosa ${ }^{2}$ & 4637 & 6709 & 583 & 11929 \\
\hline & $\mathrm{AN}^{\mathrm{b}}$ & - & 1 & - & 1 \\
\hline \multirow[t]{3}{*}{ Total } & Votos $^{2}$ & 777552 & 579886 & 63106 & 1420544 \\
\hline & $\%$ & 54.7 & 40.8 & 4.5 & 100.0 \\
\hline & $A N^{b}$ & 51 & $39^{d}$ & $2^{e}$ & 92 \\
\hline
\end{tabular}

- Región I: Estelí, Madriz y Nueva Segovia; II: León y Chinandega; Ill: Managua; IV: Carazo, Masaya, Granada, Rivas; v: Boaco y Chontales; vi: Matagalpa y Jinotega; vil región autónoma Atlántico Norte; viI: región autónoma Atlántico Sur; $\mathrm{x}$ : Río San Juan, " Votos válidos para presidente y vicepresidente. ${ }^{b}$ Representantes en la Asamblea Nacional. " Corresponde al Partido Social Cristiano. d A los 38 representantes se suma el candidato a presidente por haber obtenido más de $1 \%$ de la votación total. ${ }^{~ A d e m a ́ s ~ d e l ~ r e p r e-~}$ sentante del PSC, ingresa a la Asamblea Nacional el candidato a presidente del MUR, por haber obtenido más de $1 \%$ de la votación total.

Fuente: República de Nicaragua, Consejo Supremo Electoral. 


\section{Cuadro 2 \\ RESULTADOS POR REGION DE LAS ELECCIONES \\ DEL 25 DE FEBRERO DE 1990}

UNO FSLN Otro Total

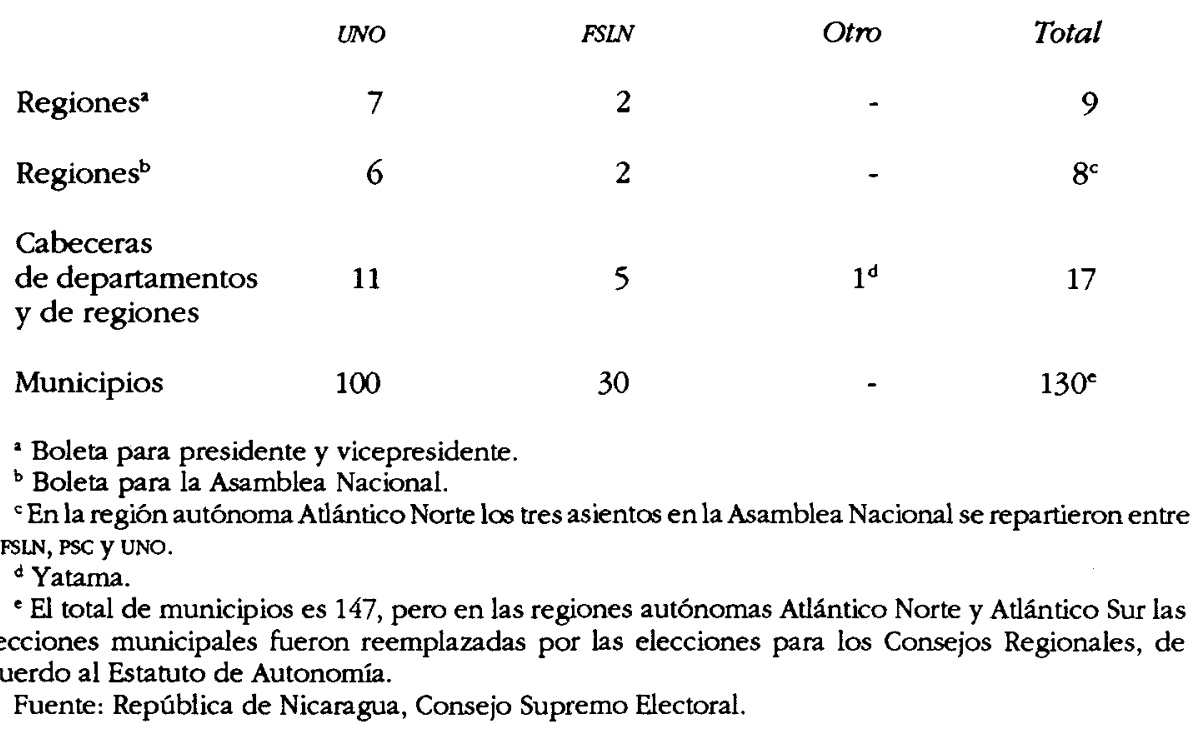

tagalpa, Somoto, Rivas, Masaya, Granada y Bluefields, donde obtuvo la mayoría en el Consejo Regional), y 100 de 130 municipios. El FSLN perdió en las dos. regiones autónomas de la Costa Atlántica -en las que cosechó casi exclusivamente el voto de la población mestiza; indios y creoles votaron en contray en municipios y poblados caros a la tradición sandinista: Palacagüina, Niquinihomo (cuna del general Sandino), La Libertad (cuna de Daniel Ortega y del cardenal Obando). Las zonas de guerra tampoco le fueron más favorables: salvo Río San Juan, perdió en todas las demás, y aunque triunfó en la región I, fue vencido por la UNO en los distritos electorales más próximos a la frontera hondureña (cuadro 2).

El predominio de la UNO tiene lugar en un sistema bipartidista efectivo donde ni ésta ni el FSLN contarán con mayoría absoluta. La necesidad de negociaciones y acuerdos se verá complicada por la fuerte polarización ideológica. El peso reducido del MUR y el PSC inhibe sus aspiraciones de presentarse como actores estratégicos para romper la previsible neutralización de los contrarios en la Asamblea Nacional.

Ahora bien: ¿por qué tantos nicaragüenses votaron por una opción electoral públicamente apoyada por el gobierno de Estados Unidos? ¿Por qué más de la mitad del electorado se inclinó por rechazar al sandinismo y apoyar la fórmula más claramente ligada a la política intervencionista de la Casa Blanca?

La información disponible, con un máximo de desagregación de los resultados a nivel de circunscripción electoral, sólo permite avanzar hipótesis. Los procesos electorales son realidades extremadamente complejas porque el re- 
sultado global depende de un enjambre de decisiones individuales y simultáneas, sobre las cuales es imposible incidir de manera directa y segura. Pero es posible tratar de identificar algunos de los factores que influyeron en el voto mayoritario del domingo 25 de febrero.

Ante todo hay que despojarse de lugares comunes y estereotipos ideológicos, tanto los que explican lo que pasó el 25 de febrero como resultado de la "compra de votos" por el gobierno de Estados Unidos (la CIA) o el financiamiento externo a la campaña electoral de la UNO, como los que señalan el repudio ciudadano a la corrupción de la dirigencia sandinista. ${ }^{17} \mathrm{Y}$ también evitar posiciones petulantes del tipo "te lo dije", porque así como hubieron "sandinistas del 20 de julio", ahora están floreciendo los profetas del 26 de febrero.

Las elecciones del 25 fueron el resultado de un proceso condicionado en sus aspectos fundamentales por una década de guerra contrarrevolucionaria que provocó miles de muertos, heridos y mutilados, destrucción de la infraestructura económica y social, movilización de centenares de miles de personas -al servicio militar, a los campamentos de reasentamiento, migraciones a las ciudades para huir de los ataques-, desabasto de productos básicos: en pocas palabras, una década de vida dura e inseguridad. La gente votó contra esto. El sandinismo no creó esta situación, pero fue el gobierno quien la administró.

La gente votó ante todo por el fin de la guerra, y es evidente que el discurso de la unO tuvo mayor credibilidad que el del FSLN, y fue en efecto más convin-

${ }^{17}$ Vid. en este último sentido las declaraciones de Moisés Hassan a la agencia AFP, El Día, 2 de marzo de 1990, México. cente. Doña Violeta prometió acabar con el servicio militar -una propuesta que venía sosteniendo desde mucho antes del inicio de la campaña electoralmientras que lo más que sugirió el FSLN, y apenas en las postrimerías de la campaña, fue "estudiar la cuestión" ${ }^{18}$ Además, si según el discurso sandinista el responsable de la guerra era el gobierno de Estados Unidos, es posible que mucha gente haya pensado que votando por la opción de la Casa Blanca las probabilidades de poner fin a la guerra serian infinitamente mayores que ratificando a un partido, y una fórmula presidencial, cuyo enfrentamiento con Washington es más que notorio. Por si quedaran pocas dudas, el presidente Bush, su secretario de Estado, la dirigencia de la contra, bombardeaban a la población con mensajes y declaraciones univocos: mientras haya sandinismo habrá guerra, y algunos elementos de la conducta del gobierno sandinista reforzaban el temor y la inseguridad de la gente. ${ }^{19}$ Finalmente, Daniel Ortega podia dejar de vestirse de uniforme, pero nadie puede dudar que doña Violeta no es un militar.

${ }^{18}$ La Dirección Nacional del fsin habría discutido la conveniencia de anunciar, en el acto de cierre de campaña electoral, la abolición del servicio militar, descartándosela por considerarse que tal anuncio de último momento podria haber sido tomado como una muestra de oportunismo del candidato presidencial del FSLN.

${ }^{19}$ El 27 diciembre de 1989, en plena invasión norteamericana a Panamá, la comandancia general del Ejército Popular Sandinista difundió a través de los medios de comunicación una "Orientaciốn" a todas sus unidades y a "las instituciones. del Estado y gobierno a todos los niveles" frente a la situación creada por la invasión norteamericana a Panamá. Entre otras cosas esta "Orientación" planteaba: "Al inicio de la intervención yanqui, todas las unidades militares permanentes, de reserva, de Milicias Populares Sandinistas y de los órganos de contrainteligencia militar, en estrecha cooperación con los órganos de seguridad del 
En estas condiciones, la posibilidad de un voto popular por la UNO fue ideológicamente descartada a priori por el sandinismo por implicar la suposición de simpatías de la gente hacia la potencia agresora -una especie de traición a la patria-, cuando lo que posiblemente hubo fue simple instinto de conservación: las madres y los padres no querían que sus hijos fueran enviados a la guerra, $y$ los muchachos tampoco. Pienso que si fuéramos a establecer un rango de factores por orden de importancia, éste fue el que incidió de manera decisiva en la orientación mayoritaria del voto, el domingo 25 de febrero. Un voto que obedeció a consideraciones prácticas de sobrevivencia antes que a motivaciones ideológicas abstractas.

Pero existieron además otros factores. El voto mayoritario por la UNO puede haber sido también el resultado de una política económica de ajuste que deterioró salarios, redujo y encareció el consumo básico, aceleró el colapso de los servicios básicos de salud y educación y

Estado, aplicarán los planes de neutralización, de corte y ejecución, de todos aquellos elementos vendepatrias más recalcitrantes que tanto abierta como solapadamente han venido alentando la intervención yanqui." Dada la identificación, en la propaganda y los medios de comunicación sandinista, de la uNocon la Guardia Nacional somocista, la Casa Blanca y con las tropas intervencionistas en Panamá -El Nueun Diario, 28 de diciembre de 1989,3 de enero de 1990 , etc. - no parece excesivo pensar que la imagen de un baño de sangre, poco propicia para un clima preelectoral, estuvo presente en la mente de muchos. Tanto más que cuando, dos días después, la uno reclamó ante el Consejo Supremo Electoral por este comunicado, la máxima autoridad electoral se limitó a dirigir al Ministerio de Defensa, casi una semana más tarde, una tibia solicitud de "explicación del alcance y significado" del mencionado párrafo y su preocupación de que el mismo "restrinja los derechos y garantías establecidos en nuestra Carta Magna", Barricada, 3 de enero de 1990. revirtió las grandes conquistas sociales de los años iniciales de la revolución, eliminó el racionamiento físico de los productos de primera necesidad -que garantizaba un acceso seguro para todo el mundo- por el racionamiento del mercado y los precios altos sólo accesibles a los más ricos y endeudó hasta el tuétano a los campesinos. No hubo un "managuazo" equivalente al "caracazo", pero hubo disminución de los niveles de movilización social y, finalmente, un "domingazo": la fantasía de un programa de ajuste con aquiescencia popular probó ser un mito de tecnócratas que costó muy caro a la revolución. ${ }^{20}$

Además la política económica estuvo rodeada de una retónica que agravió adicionalmente a los que perjudicaba económicamente al mismo tiempo que continuaba las concesiones a los grupos acomodados. Cuando los obreros de la construcción y de la mecánica automotriz se declararon en huelga en demanda de mejoras salariales, la respuesta del gobiemo fue acusarlos de estar al servicio del gobierno de Estados Unidos y lanzarles la policía; cuando los maestros y los trabajadores de salud reclamaron mejores salarios al presidente Ortega, éste les endilgó un discurso sobre sus

${ }^{20} \mathrm{El}$ comandante Daniel Ortega parece haberlo advertido, tardiamente, dos dias después de las elecciones: "Pero qué pasa, ha habido otro sector importante de la población que tenemos que respetarlo, porque no es el sector extremista y sinvergüenza; ellos no lo son ni malquieren a la revolución, sino que han creído que pueden mejorar la situación con la oposición." Discurso a las masas congregadas ante el Complejo Olof Palme, Managua, el 27 de febrero de 1990. Vid. asimismo el equilibrado artículo de José Manuel Ruiz Marcos, "Por qué perdió el FsLN", El Nuevo Diario, 6 de marzo de 1990 , y las declaraciones del comandante Bayardo Arce en su visita a México, La Jornada, 11 de marzo de 1990. 


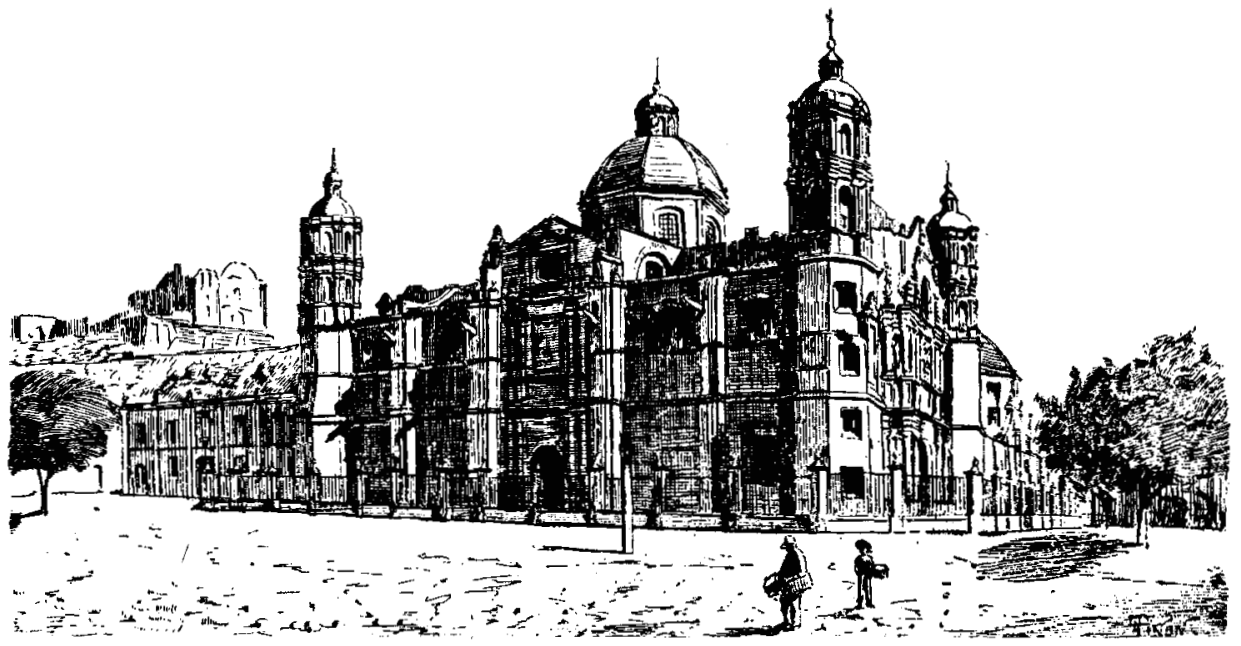

obligaciones morales respecto de la población, ${ }^{21}$ y cuando un año después algunos sectores del magisterio declararon, por los mismos motivos, la huelga, sobrevino la usual acusación de estar al servicio de Estados Unidos. Cuando las cooperativas de producción -que representan 50\% del empleo industrial y $21 \%$ del producto respectivo- reclamaron por las altísimas tasas de interés, el ministro de Finanzas les contest $\delta$ que a menos que se ajustaran a la nueva política, muchas de esas cooperativas tendrían que "desaparecer irremediablemente". ${ }^{22}$ En sintesis, una política económica convencional que favoreció a los ricos y perjudicó a los pobres, y que además los agredió ideológicamente y ratificó en el discurso oficial la ausencia de un espacio legítimo para buena parte de las

${ }^{21}$ Barricada, 18 y 19 de junio de 1988.

${ }^{22}$ Barricada, 30 de junio de 1988. bases sociales del sandinismo. Con el agravante que las concesiones efectuadas a los primeros -y que éstos aceptaban siempre demandando más- no alteraron su comportamiento político. En estas condiciones, las referencias a una orientación socialista, bien que democrática, del régimen sandinista, precisamente en momentos en que el viraje hacia la derecha era más notorio, resultaron ser una curiosidad semántica que conmocionó a pocos. ${ }^{23}$

${ }^{23}$ Vid. los discursos del presidente Ortega presentando el programa de ajuste de junio 1988 (Barricada, 15 de junio de 1988), en ocasión del IX aniversario de la revolución (Barricada, 20 de julio de 1988), y el informe a la Asamblea Nacional del 30 enero de 1989 sobre un nuevo programa de ajuste (Barricada, 31 de enero de 1989). Es interesante señalar que estas proclamaciones no suscitaron reacciones en sectores tradicionalmente proclives al escándalo-grupos políticos derechistas, agencias del gobiemo de Estados Unidos-; las políticas efectivas del gobierno sandinista les 
La cuestión de las candidaturas también debe haber jugado un papel. A pesar de sus esfuerzos, de sus camisas juveniles y del estilo bullanguero de su campaña, Daniel Ortega nunca pudo desprenderse de su imagen de comandante, y habría sido tremendamente dificil que lo lograra. La UNO en cambio presentó como candidata a un ama de casa, una madre, viuda de un hombre célebre, que no tiene una versación particularmente notable en política ni pretende aparentarlo, con un discurso que apela a, y practica, todos los matices del sentido común nicaragüense y que activa, posiblemente sin saberlo, las más profundas asociaciones de una sociedad machista en torno a la madre: ¿qué mejor símbolo para una propuesta de paz? Donde el FSLN veía limitaciones y ridículos, es posible que una porción grande de la población haya identificado méritos y virtudes, y los ataques personalizados sobre dona Violeta no hicieron más que reforzar ese sentimiento. ${ }^{24}$

resultaban más convincentes que su discurso. En cambio el discurso oficial impactó en algunos sectores de la Iglesia, que a partir de él dieron por sentado $\sin$ más el carácter socialista de la experiencia sandinista; Instituto Histórico Centroamericano, "¿Hacia dónde vamos?", Envío, edición especial para el décimo aniversario de la revolución, Managua, julio de 1989, pp. 1-51; Xavier Gorostiaga, "Legados, retos y perspectivas del sandinismo 1979-1989", Nueva Sociedad, núm. 104 , noviembre-diciembre de 1989, pp. 24-40.

${ }^{24}$ Por ejemplo, los intentos de los medios de comunicación sandinistas -incluido el diario $\mathrm{Ba}$ rricada, dirigido por su hijo Carlos Fernando-de privar a doña Violeta Barrios de Chamorro de su apellidode casada en las menciones que se hacian de ella, o las cartas públicas que su hija Claudia -funcionaria del gobierno sandinista- le dirigió criticando su posición politica (Barricada y El Nuevo Diario, 26 de octubre de 1989; Excélsior, 12 de febrero de de 1990; La Jormada, 23 de febrero de 1990) o las caricaturas que se publicaban en $E l$ Nuevo Diario -dirigido por su cuñado- habrian
En este mismo orden de ideas, la decisión sandinista de organizar una campaña electoral festiva, con apelaciones a la juventud inspiradas en la simbología de los medios de comunicación que en los años iniciales de la revolución se juzgaban "burgueses" y recurriendo a lo que, también en aquellos años, se consideraba "diversionismo ideológico", parece haber chocado con el estado de ánimo de muchos nicaragüenses. En particular la generosa distribución de regalos importados -prendas de vestir,

generado actitudes de solidaridad a dona Violeta en quien alguna gente parece haber visto el típico caso de una madre maltratada por sus hijos. A principios de septiembre de 1989, en su primer discurso -que el derechista diario La Nación de Costa Rica juzgó como "de muy modestas pretensiones políticas" (11 de septiembre 1989)- en la ciudad de Juigalpa, departamento de Chontales, doña Violeta respondió a la campaña de los diarios Barricada y El Nuevo Diario que se negaban a mencionar su apellido de casada en un reconocimiento implícito de las simpatias de muchos nicaragüenses por su asesinado esposo, señalando que, a pesar de esos periódicos, toda Nicaragua sabía que ella se encuentra "marcada por el fierro de los Chamorros", El Nuevo Diario, 11 de septiembre de 1989. Los medios de comunicación sandinistas en las semanas siguientes encontraron en esta frase ocasión para escarnecer a doña Violeta, señalando que en el campo nicaragüense "el fierro" es el instrumento con que se marca al ganado vacuno para identificar a quién pertenece, René Corea en El Nuevo Diario, 13 de octubre de 1989. Poco después, el diario La Prensa publicó en su página editorial una nota en la que, tras ilustrar sobre el papel de la familia Chamorro en la historia de Nicaragua, mencionaba una lista (posiblemente incompleta) de 25 miembros de la familia Chamorro que eran en ese momento funcionarios de alto nivel del gobierno sandinista, y concluía: "Para ironia del destino... no encontré en el gobiemo tantos Sandinos o Fonsecas como Chamorros. Seguimos pues, lès guste o no les guste, con el fierro de los Chamorros", Ignacio Fonseca, " "El fierro de los Chamorros' en la era sandinista ", La Prensa, 17 de octubre de 1989. 
juguetes para niños, emblemas, artículos de uso personal, etc.- en los actos de campaña y en las giras de los candidatos sandinistas, contrastaba con el empobrecimiento marcado de la población por efectos de la crisis y la guerra, y fortalecía la plausibilidad del mensaje de la UNO que asociaba la riqueza de los funcionarios al empobrecimiento dela gente.

Es posible que también haya habido un ajuste de cuentas, lo que se conoce como "voto castigo". Muchos electores encontraron en el voto secreto y libre el instrumento adecuado para repudiar aspectos concretos de la gestión sandinista que les resultaron directamente irritantes: la prepotencia de tal o cual burócrata, el enriquecimiento injustificado de un vecino funcionario; el chantaje sexual del jefe; la falta de libros de texto en las escuelas mientras se imprimían decenas de miles de ejemplares de novelas, testimonios y discursos de los dirigentes; el calamitoso transporte público junto al auto con aire acondicionado del director... Muchos de estos aspectos no fueron inventados por los sandinistas: constituyen parte consustancial del prebendalismo tradicional del Estado y el ejercicio del poder en este tipo de sociedades. Pero los sandinistas hicieron poco por eliminarlo, en muchos casos contribuyeron a reproducirlo, y en la medida en que el proceso revolucionario se enredaba en sus propias ambigüedadesy en su incapacidad de defender los avances del pasado, se hizo mucho más notorio y repudiable.

En estas condiciones de agresión, crisis económica, política de ajuste, distanciamiento creciente del discurso sandinista respecto del clima político efectivamente existente, el triunfalismo de la consigna "Todo será mejor" de las aspiraciones reeleccionistas del FSLN debió sonar a burla para mucha gente, oa "más de lo mismo", después de once años de gestión gubernativa ininterrumpida de Daniel Ortega y Sergio Ramírez. ¿Por qué esperar algo nuevo de ellos? Y no sólo de ellos, sino de toda la pirámide de autoridad que desciende y se ensancha cuanto más se aproxima a la vida cotidiana de la gente. Porque es posible que para muchos el problema no haya sido tanto la reelección del presidente y el vicepresidente, como la certeza de que esa reelección aparejaba que todo iba a seguir siendo igual: el jefe prepotente, el vecino arribista, la vida cara, la falta de empleo. Por esto, y no por una ideología anticomunista o simpatías por la contrarrevolución y Estados Unidos, muchos de los que participaron con entusiasmo del extraordinario acto de fin de campaña del FSLN la noche del 21 de febrero, votaron por la UNO la mañana del 25 : porque cuando volvieron a sus casas se encontraron otra vez con la paila del arroz vacía, con el espacio vacante del hijo que fue reclutado al servicio militar, o con la foto del que murió víctima de la contra, o con el auto nuevecito del vecino...

El mayor error de los observadores y analistas, sobre todo de los mâs próximos al FSLN, fue el de exagerar la importancia de los factores externos -la agresión norteamericana, la crisis internacional, la reticencia de los organismos internacionales y gubernamentales a financiar las políticas económicas- en la configuración del marcosocioeconómico de las elecciones. En consecuencia proyectaron hacia el comportamiento de los electores la racionalidad del discurso sandinista y la hipótesis de una preferencia electoral en función de razonamientos ideológicos generales -la responsabilidad de los agentes externos en el montaje del escenario de las elecciones- más que a partir de las circunstan- 
cias concretas y específicas que diseñan las condiciones de vida de la gente. Tanto más cuando la historia reciente de la revolución sandinista ofrece no pocos ejemplos de grupos de población que se sumaron a la contra en respuesta a aspectos que juzgaron negativos de las políticas gubernamentales, y que posteriormente optaron por desalzarse y reintegrarse a la vida civil como resultado de cambios en las políticas gubernamentales y en los estilos políticos del sandinismo, más que de modificaciones políticas o económicas de los agentes externos. 25

Finalmente, hay que prestar la debida atención a que, a pesar del cúmulo de circunstancias adversas que enmarcaron el proceso electoral, hay un $40 \%$ de nicaragüenses que optó por continuar por la senda dura a pesar de todo. Algunos, porque la senda dura estuvo matizada por no poca miel; pero la mayoría, sin lugar a dudas, por convicción y esperanza. Este $40 \%$ coloca al FSLN como el partido político individual más fuerte de Nicaragua.

\section{LAS ENCUESTAS PREELECTORALES}

El resultado de las elecciones contrasta también con la imagen que se había difundido a través de las encuestas preelectorales que con verdadera profusión diversas agencias llevaron a cabo desde fines de 1989 por cuenta de variados clientes. Debe señalarse sin embargo que los márgenes de abultada ventaja a

\footnotetext{
${ }^{25}$ Carlos M. Vilas, "War and revolution in Nicaragua. The impact of the US counter-revolutionary war on the sandinista strategies of revolutionary transition", en Ralph Miliband et al. (comps.), The Socialist Register 1988, Merlin Press, London, 1988, pp. 182-219.
}

favor del candidato presidencial del FSLN emanaban fundamentalmente de encuestas realizadas por medios simpatizantes del sandinismo, y que en general la prensa internacional tendió a dar más difusión a éstas que a las que presentaban un panorama menos rojinegro.

El cuadro 3 presenta una perspectiva de las encuestas de opinión efectuadas en enero y febrero de 1990. También incluye la encuesta de la Fundación Manolo Morales (vinculada al Partido Popular Social Cristiano) por ser una de las primeras en arrojar resultados adversos a las aspiraciones del FSLN mucho antes que se constituyera la UNO y que iniciara la campaña electoral.

Se aprecia que en general las encuestas que adjudicaban al candidato presidencial del FSLN el triunfo electoral, fueron llevadas a cabo por agencias o para clientes vinculados al sandinismo o simpatizantes de él, y que un resultado opuesto se obtuvo en las encuestas patrocinadas o ejecutadas por organizaciones cuyas simpatías reales o presuntas se dirigían hacia la oposición. Las excepciones más notorias son las encuestas efectuadas para la cadena Univisión -aunque una primera encuesta hecha para esta misma cadena a fines de 1989 reveló una intención de voto por doña Violeta mucho mayor que para Daniel Ortega-y el Washington Post y ABC News. El caso más notorio es el de las encuestas ejecutadas por la empresa nicaragüense ECO (Encuestas y Consultas de Opinión), una firma ligada al gobierno sandinista, para la Universidad Centroamericana, una institución de educación superior muy vinculada al gobierno y activa productora de ideología de apoyo al gobierno, y con otra orientación, las encuestas organizadas por Vía Cívica para el NED, y Borge y Asociados para el diario La Prensa. 
Cuadro 3

PRINCIPALES ENCUESTAS PREELECTORALES

\begin{tabular}{|c|c|c|c|c|c|}
\hline Empresa & Cliente & Fecha & Intención d & voto (\%) & Otros \\
\hline & & & $\begin{array}{l}\text { Violeta } \\
\text { Cbamorro }\end{array}$ & $\begin{array}{l}\text { Daniel } \\
\text { Ortega }\end{array}$ & \\
\hline $\begin{array}{l}\text { Borge y } \\
\text { Asociados }\end{array}$ & $\begin{array}{l}\text { Fundación } \\
\text { Manolo } \\
\text { Morales }\end{array}$ & $4 / 89$ & 51.7 & 42.3 & 6.0 \\
\hline $\begin{array}{l}\text { Greenberg- } \\
\text { Lake/Itztani }\end{array}$ & $\begin{array}{l}\text { Hemispheric } \\
\text { Initiatives }\end{array}$ & $1 / 90$ & 28.9 & 61.4 & 9.7 \\
\hline ECO & $\begin{array}{l}\text { Universidad } \\
\text { Centroame- } \\
\text { ricana }\end{array}$ & $1 / 90$ & 23.2 & 73.9 & 2.4 \\
\hline DOXA & DOXA & $1 / 90$ & 48.8 & 39.3 & 11.9 \\
\hline Via Civica & $\begin{array}{l}\text { National } \\
\text { Endowment } \\
\text { for Democracy } \\
\text { (NED) }\end{array}$ & $1 / 90$ & 59.3 & 30.2 & 10.4 \\
\hline Bendixen & Univisión & $1 / 90$ & 38.1 & 57.6 & 4.3 \\
\hline ECO & $\begin{array}{l}\text { Universidad } \\
\text { Centroamericana }\end{array}$ & $2 / 90$ & 28.4 & 67.9 & 3.7 \\
\hline $\begin{array}{l}\text { Belden/ } \\
\text { Itztani }\end{array}$ & $\begin{array}{l}\text { Washington } \\
\text { Post/ABC News }\end{array}$ & $2 / 90$ & 38.1 & 57.1 & 4.8 \\
\hline $\begin{array}{l}\text { Borge y } \\
\text { Asociados }\end{array}$ & IPCE/La Prensa & $2 / 90$ & 54.3 & 38.6 & 7.1 \\
\hline
\end{tabular}

La cuestión central en torno a las encuestas es la validez de este tipo de técnicas de investigación en contextos socioculturales tan poco semejantes a los que corresponden al desarrollo de las mismas. Este es un tema relativamente trabajado en las cienciassociales en América Latina, circunstancia que, sin embargo, no impide su difusión ni mucho menos la generación de entusiasmo cuando los resultados son favorables a lo que uno cree o le gusta. Esta actitud estuvo presente en el rápido cambio de opinión de la dirigencia sandinista a medida que las encuestas mostraban preferencias hacia el candidato del FSLN. Debe destacarse en talsentido el contraste entre el tono burlón y despreciativo de las referencias del comandante Daniel Ortega a las encuestas en su discurso conmemorativo del $\mathrm{X}$ Aniversario de la Revolución (19 de julio 1989) en la plaza Parque Carlos Fonseca Amador de Managua -cuando la única encuesta sobre intención de voto era la ya referida de la Fundación Manolo Morales-, y. el despliegue publicitario que el Sistema Sandinista de Televisión, las emisoras radiales estatales, y los diarios Barricada (órgano oficial del FSLN) y $E l$ Nuevo Diario acordaban a los resultados 
de las encuestas en las que Daniel Ortega aparecía como ganador; algunas de ellas fueron incluso presentadas en ampulosas conferencias en el Club Internacional de Prensa.

Puede pensarse que la resistencia cultural de la mayoría de la gente a este tipo de técnicas se haya incrementado en la medida en que de más en más éstas aparecían como auspiciadas por el gobierno sandinista, y que no sólo las respuestas "no sabe" encubrieran por temor un voto opositor, ${ }^{26}$ sino que detrás de una buena parte de las respuestas favorables a Daniel Ortega se encontrara una actitud similar: contestarle al encuestador, presumiblemente enviado por el gobierno, tal como se pensaba que éste quería que se le contestara. Esto explicaría que, por el contrario, las encuestas organizadas por instituciones ligadas a la oposición hayan resultado más acertadas.

En todo caso, es evidente que fallaron los indicadores utilizados por el FSLN y la mayoría de los observadores simpatizantes con él para anticipar comportamiento electoral. No sólo en las encuestas, sino también en la asistencia a actos públicos. La masividad de una manifestación, o una plaza llena, nunca han sido buenos indicadores de popularidad, sino usualmente de capacidad de transporte. $\mathrm{Y}$ así como hubieron denuncias -muchas de ellas comprobadas-de que la UNO repartía billetes de cinco dólares entre los asistentes a sus movilizaciones, las camisetas, sombreros, mochilas escolares, encendedores, etc. que el FSLN distribuyó generosamente tenían un valor no inferior, y a menudo superior. Pero aun sin estímulos materiales, la masividad de una concentración sirve poco en el momento de medir popularidades $y$

\footnotetext{
${ }^{26}$ Como acertadamente interpretaron algunos lúcidos analistas del FSLN.
}

afectos políticos cuando la gente tiene la posibilidad de expresarse libremente por la vía electoral. Se va a una movilización por voluntad y convicción; también se va por curiosidad, o por falta de valor para no ir, o porque de todos modos hay transporte para el regreso. ${ }^{27}$

Porúltimo, en concentraciones públicas como las que organizó el FSLN en su campaña electoral, en las que los discursos de los dirigentes se complementaban con actuaciones de las orquestas y estrellas de moda -algunas de ellas traídas especialmente desde el extranjeroy despliegues de reinas de belleza, era imposible saber cuánta gente iba a escuchar a Daniel Ortega, y cuánta simplemente a bailar con la Sonora Dinamita o a alimentar fantasías eróticas.

\section{LO QUE VENDRÁ}

En esta última parte, la más especulativa de todo el documento, voy a plantear a manera de hipótesis super conjeturales algunas ideas acerca de lo que puede pasar en Nicaragua y en la región a partir de estas sorprendentes elecciones.

Hay que evitar reacciones catastrofistas: ni la revolución se vendrá abajo en lo inmediato, ni los sandinistas podrán torpedear el gobierno de la UNO. Negociación será el nombre del juego. Esta

${ }^{27}$ No está de más recordar que, por ejemplo, el 31 de agosto de 1955 el entonces presidente de Argentina Juan D. Perón, Llenó la Plaza de Mayo de entusiastas partidarios, y 20 días después la misma plaza se llenó de partidarios del gobierno militar que acababa de derrocarlo. El 4 de septiembre de 1973 el presidente Salvador Allende habló ante la Plaza Bulnes de Santiago de Chile, rebosante de partidarios de la Unidad Popular, y tres semanas más tarde esa misma plaza se llenó de partidarios del golpe militar encabezado por Pinochet. 
afirmación implica como condición de viabilidad que tanto dentro de la UNO como del FSLN prevalecerán las posiciones menos extremas o "duras" -algo que ha sido evidente durante todos estos años en lo que al sandinismo respecta-, y que el gobiemo de Estados Unidos, en ejecución de la estrategia pragmática de James Baker, el secretario de Estado, forzará a la desmovilización de lo que resta de la contra, aunque será prácticamente imposible impedir la subsistencia de pequeñas bandas armadas que merodearán en algunas zonas rurales y mantendrán a la población en ascuas. El gobierno de Violeta Barrios tampoco podrá garantizar a plenitud que elementos de la ex Guardia Nacional, o de la contra, traten de ejecutar venganza $o$ cobrarse cuentas contra antiguos funcionarios sandinistas. Estas situaciones obedecerán más que a los colores que tiñen el conflicto político, o a su dramática intensidad, a las características más profundas de las sociedades agrarias. Es probable que el cardenal Obando actuará también en un sentido diaıoguista y moderador a pesar de su prolongado enfrentamiento al régimen sandinista: más que nadie, él es el gran vencedor del domingo 25. El acuerdo celebrado el 23 de marzo en Tegucigalpa por los principales mandos contrarrevolucionarios con representantes de Doña Violeta, en el que se comprometen a iniciar el proceso de desalzamiento a más tardar el 20 de abril, señala el triunfo (¿momentáneo?) de los moderados incluso dentro de la contra.

En una sociedad en la que las estructuras de parentesco se articulan con la estratificación en clases y son a veces más importantes que las ideologías para explicar los procesos políticos, el viejo tronco conservador, que atraviesa por igual al sandinismo y al núcleo de la
UNO, servirá de puente de entendimiento para evitar rupturas -incluyendo el tratamiento de la cuestión del ejército. ${ }^{28}$ Pero al mismo tiempo esta situación contribuirá a profundizar los antagonismos dentro de la UNO entre los señores de estirpe conservadora, blancos, educados en el exterior, y sus socios plebeyos socialistas, comunistas, liberales, mestizos y "chapiollos". Los asesores más próximos a doña Violeta y quienes conducen las negociaciones con el FSLN para la transferencia del gobierno pertenecen casi en su totalidad al viejo tronco conservador y a las familias más tradicionales de la vieja Nicaragua. Un perfil que no es demasia do distinto al del gobierno sandinista y la oficialidad superior del ejército.

La negociación se impondrá de todos modos más por necesidad que por gusto. Ni la UNO ni el FSLN disponen de fuerza suficiente para hacer o para impedir por sí solos. La constitución aprobada por el sandinismo en enero de 1987 crea una presidencia fuerte al estilo mexicano, pero de todos modos muchas de las reformas propuestas por la UNO implican modificaciones constitucionales para las cuales se requiere una mayoría le dos tercios de la que carece. El FSLN, al contrario, no podrá impedir la modificación de leyes importantes para su concepción del estado -el servicio militar, la asignación de recursos por la vía presupuestaria, los alcances de la reforma agraria, etc.- para los cuales bastará con una mayoría simple ( 47 votos) que la UNO posee holgadamente en la medida en que mantenga su unidad. Hasta el momento la precariedad de tal unidad es notoria, y el FSLN apuesta a la

${ }^{28}$ Carlos M. Vilas, "Nicaragua poselectoral: La cuestión del EPS", La Jomada, 5 de marzo de 1990.
1

4

3 
vieja práctica de divisiones y enfrentamientos de la política tradicional para asegurarse su papel de único partido sólido, y efectivamente mayoritario.

En efecto, los 51 asientos parlamentarios obtenidos por la UNO se desglosan en cinco grandes corrientes ideológicas, o familias de partidos: trece escaños para los partidos de orientación conservadora, doce para los de orientación liberal, once para los socialdemócratas, diez para la familia socialcristiana, más tres asientos para el Partido Comunista y dos para el PIAC. Por otro lado, los dos tercios requeridos para modificar la constitución significan 55 votos; aun suponiendo que la UNO mantuviera la unidad y pudiera ganarse a los representantes del MUR y el PSC, seguirían faltándole dos votos, que forzosamente deberán salir de la bancada sandinista. Por todo esto, es de esperar que la Asamblea Nacional desempeñe en la etapa que se abre el 25 de abril, un papel mucho más dinámico que el de casi apéndice del poder ejecutivo que cumplido durante el sexenio sandinista.

La negociación y los arreglos regirán en todo caso por arriba y en el seno de los grupos sociales tradicionalmente dominantes; por debajo, es decir, en las llanuras del pueblo, los ajustes de cuentas tendrán lugar. A partir de los acuerdos de Costa del Sol (febrero de 1989) el gobierno sandinista puso en libertad a todos los antiguos guardias nacionales y miembros de la contra condenados por delitos y violaciones a los derechos humanos; la medida se adoptó apuntando a la opinión pública internacional, como una de las maneras de prevenir el cuestionamiento externo de una victoria electoral que se consideraba al margen de cualquier duda. Pero ahora los asesinos andan sueltos. También reclaman revancha, o al menos compensación, los que fueron confiscados por haber abandonado sus bienes al irse de Nicaragua aún sin involucramiento en actividades contrarrevolucionarias. Todos los que perdieron con la caída del somocismo vuelven hoy en busca de lo que consideran suyo.

La derrota electoral incidirá fuertemente en el FSLN como partido, en su estructura, en su conducción, en sus bases. El sandinismo sigue siendo, de lejos, el mayor partido político de Nicaragua, pero habrá que ver cómo se amolda a su vida en el llano. Situación que no es sencilla, pues lo que hoy conocemos como FSLN tiene que ver mucho más con la experiencia de once años de control casi absoluto del gobierno y el Estado, y de acceso a buena parte de sus recursos, que a la organización guerrillera de la década de 1970. El FSLN deberá democratizarse; la estructura organizativa rígida y verticalista, propia de un partido confundido en muchos aspectos con los aparatos del Estado, es ina decuada para la nueva etapa. El futuro de la dirección nacional colectiva y de la Asamblea Sandinista aparecen cargados de interrogantes, lo mismo que el mantenimiento y ampliación del reclutamiento de adherentes. En lo que toca a esto último todo lleva a pensar en que habrá de registrarse una reducción de sus bases, al menos los que se incorporaron al FSLN no tanto por convicción ideológica como por deseos de progresar en la vida. Algo similar es de esperarse en lo referente a las organizaciones de masas de afiliación sandinista, en primer lugar en el movimiento obrero urbano, ante la escasa eficacia reivindicativa de la Central Sandinista de Trabajadores durante todos estos años, y el nuevo clima político que beneficiará ante todo a las organizaciones sindicales antes opositoras. 
La febril actividad legislativa de la Asamblea Nacional después del 25 de febrero apunta a crear condiciones legales para la nueva etapa del FSLN como partido opositor y despojado de su articulación estatal. Se aprobó la ley de autonomía para la Universidad Nacional -destino seguro de una gran cantidad de cuadros y dirigentes sandinistas-; se abolieron los controles estatales sobre los medios de comunicación y el monopolio estatal de la televisión; se derogaron los artículos del código del trabajo (que data del gobierno del primero de los Somoza) que autorizaban al despido sin aviso ni causa previos; se aprobó una nueva ley de inmunidad que ampara a los funcionarios públicos que entre el 19 de julio de 1979 y el 25 de febrero de 1990 pudieran haber cometido delitos en ejercicio de sus funciones -incluidos el fraude, el peculado y la malversación de fondos- y que aún no hubieran sido motivo de causa penal. ${ }^{29}$

En materia de política económica, el margen de acción frente a la crisis es tan estrecho que tanto el FSLN como la UNO encararían las cosas de manera más o menos parecida, sin perjuicio de los ataques, burlas e invectivas reciprocas. Sobre la base de las políticas de ajuste que han venido ejecutándose desde junio de 1988, la UNO buscará la reactivación de la economía a través de la dinamización del sector exportador de productos agropecuarios e industriales

${ }^{29}$ La ley ampara a los siguientes funcionarios: presidente y vicepresidente de la república, representantes ante la Asamblea Nacional, magistrados de la Corte Suprema de Justicia, Consejo Supremo Electoral y tribunales de apelaciones, contralor general de la república, ministros y viceministros, presidentes o directores de entes autónomos y gubernamentales, comandante en jefe del EPS y jefe de estado mayor del EPS. no tradicionales, estímulos a la actividad privada y búsqueda en el exterior de financiamiento fresco de corto plazo, y capitales de inversión. Es de esperarse que se tratará de convencer a los técnicos y profesionales que abandonaron Nicaragua durante la década pasada, que regresen al país a participar de los esfuerzos de reactivación. ${ }^{30} \mathrm{El}$ nuevo gobierno pone asimismo sus esperanzas en la repatriación de los capitales de los nicaragüenses radicados en Estados Unidos después de 1979.

Se fortalecerán las medidas ya adoptadas para la reducción del área estatal de la economía, pero el ingreso de fondos frescos permitirá cierta reactivación del gasto público. La cuestión de las propiedades por cuya expropiación o confiscación reclamen sus antiguos dueños no cuenta todavía con consenso dentro de la UNO; mientras algunos asesores de doña Violeta plantean la devolución lisa y llana de los mismos, otros, con más sentido político, proponen el pago de indemnizaciones adecuadas. Es probable que la cuestión sea procesada atendiendo a un enfoque particularista y casuístico, más que en función de cri-

${ }^{30}$ Entre 1979 y 1987 emigraron legalmente 140066 personas; de éstas casi $84 \%$ entre 1983 y 1987. Salieron de Nicaragua 62756 miembros de la PEA, $70 \%$ de ellos entre 1983 y 1987. Los profesionales y técnicos sumaron $8364 ; 83 \%$ de ellos emigró a partir de 1983; los rubros mas afectados son la ingeniería y la educación $(3776$ personas en conjunto, o $45 \%$ de los profesionales y técnicos emigrantes), Secretaría de Planificación y Presupuesto, Las migraciones intemacionales $y$ su impacto en la fuerza laboral, Managua, agosto de 1988, mimeo. Cabe señalar que mientras durante 1989 alrededor de 25 agencias informales de viajes publicitaban diariamente en La Prensa y El Nuevo Diario sus servicios de transporte terrestre hacia Guatemala y México -itinerario tradicional de los potenciales migrantes clandestinos a Estados Unidos- en marzo de 1990 los avisos se habían reducido a entre cuatro y seis. 
terios generales y objetivos. Los acuerdos celebrados entre los funcionarios del gobierno sandinista y los representantes de doña Violeta para la trasmisión del gobierno estipulan que se otorgará seguridad jurídica a las familias beneficiadas con propiedades urbanas o rurales adjudicadas por el estado antes de las elecciones del 25 de febrero, "armonizándolas con los legítimos derechos de las personas que pudieran verse afectadas en sus bienes". A tal efecto se convino en establecer "formas de compensación para las personas que pudieran resultar afectadas", una fórmula genérica que abre las puertas a todo tipo de soluciones, incluyendo la entrega de los bienes a los antiguos propietarios a cambio de una indemnización que puede ser tanto en moneda como en títulos de la deuda pública. En este contexto, la reforma agraria será sometida a revisión, y es sin duda en este terreno donde mayor intensidad pueden llegar a asumir las confrontaciones políticas.

La clave de cualquier política económica será el acceso a financiamiento de corto plazo y a capitales de inversión. Las apelaciones del gobierno sandinista obtuvieron respuestas escasas en la comunidad internacional. Esta situación contrasta con la celeridad con que la Casa Blanca levantó el embargo económico tras el triunfo de la UNO y solicitó al Congreso una ayuda de emergencia de 300 millones para la nueva administración de doña Violeta. Es evidente que Washington está firmemente interesado en que el nuevo gobierno tenga un buen principio, y ante los pasos emprendidos por la Casa Blanca puede esperarse el próximo desbloqueo de los fondos de las agencias multilaterales.

En lo inmediato lo determinante es el ciclo agrícola cuyo inicio se avecina. El nuevo gobiemo deberá acordar con el saliente cuestiones muy concretas de tipos de interés, habilitaciones crediticias, precios, disponibilidad de insumos, etc., para que la economía se ponga en marcha. Cuestiones todas en las que la ideología tiene poco que ver, si bien no es totalmente ajena.

La derrota electoral del sandinismo devuelve a Centroamérica una homogeneidad política que se había perdido en toda la década de 1980. Este es sin duda un triunfo para Estados Unidos. Es cierto que el gobierno sandinista venía dando muestras de creciente moderación en este terreno, y que la declaración de San Isidro Coronado es por demás explícita al respecto, pero de todos modos ahora el panorama regional se presenta mucho más sólido para Washington. De los tres grandes problemas que tenía hasta hace tres meses la Casa Blanca en la cuenca del Caribe-Noriega, el gobiemo sandinista, Cuba- ahora sólo queda uno. Las presiones sobre el FMLN para una negociación con el gobierno de Alfredo Cristiani se redoblarán, y el aislamiento regional de Cuba se acrecentará. Las autoridades recién electas han formulado respecto de ese país declaraciones moderadas que no permiten anticipar por ahora una ruptura de relaciones, pero sí una severa reformulación de las mismas. Cuba por su lado, agobiada por una situación económica internacional particularmente adversa, se apresuró a anunciar que, ante la falta de solicitud del gobiemo de la UNO para la renovación de convenios de asistencia económica, éstos se daban por concluidos, al igual que la asistencia derivada de acuerdos basados en coincidencias políticas entre La Habana y el gobierno sandinista. En el marco del incremento previsible de las presiones de Washington sobre la isla, no debe descartarse la hipótesis de que el gobierno de Violeta 
Chamorro será llevado a romper relaciones con el régimen de Castro: una cuestión en la que los intereses de Washington son más relevantes que las intenciones de sus protegidos. La pax americanna se ha restablecido en Centroamérica.

\section{¿QUE QUEDA DE LA REVOLUCIÓN SANDINISTA?}

Por encima del catastrofismo de los que pensaron al sandinismo como una realidad eterna, universal incluso, y de la ingenuidad de los que imaginan el poder omnipotente de Estados Unidos, la CIA, los contras y la UNO, es evidente que la derrota se refiere al gobierno sandinista, no necesariamente, o todavía, a la revolución.

Ciertamente el FSLN ha sido despojado del gobierno, a pesar de las fantasías triunfalistas -juna vez más!- de la nueva consigna "Gobernaremos desde abajo", y todas las disquisiciones acerca de si el gobiemo de doña Violeta podrá reformar la Constitución se refieren a la posibilidad de desmontar o modificar profundamente las instituciones estatales en fue la revolución cristalizó o se articuló: ejército, organismos de seguridad, espacio institucional reconocido a la participación de las organizaciones populares en el diseño de las políticas, etc.Pero una revolución no se reduce al estado, salvo en una concepción jacobina de la política, sino que existe, ante todo, en el seno de la sociedad civil.

Debe reconocerse en este sentido que el empantanamiento del proceso revolucionario en sus propias tensiones y ambigüedades es anterior a las elecciones, y que éstas sorprendieron a buena parte de las bases sociales del sandinismo en condiciones de debilidad y des- movilización. Las perspectivas de la revolución sandinista de sobrevivir a la derrota electoral de febrero dependerán, en última instancia, de la solidez del enraizamiento de las transformaciones sociales y políticas en los relieves concretos de la sociedad y de la capacidad del tejido social de resistir los intentos de revertirlas o neutralizarlas, y de la capacidad del FSLN para reasumir el liderazgo de las aspiraciones populares, que dificilmente el nuevo gobierno podrá satisfacer.

La perspectiva que se abre para Nicaragua con la victoria electoral de la UNO no es enteramente nueva; ya estaba inscrita como posibilidad en el triunfo mismo de la revolución sandinista el 19 de julio de 1979: el entonces denominado, peyorativamente, "somocismo sin Somoza", o entusiastamente por otros, "somocismo científico". ${ }^{31}$ En realidad, una estrategia de participación popular limitada, canalizada por vias institucionales y democracia electoral, como soporte de una estrategia económica de reformas tibias y conducción empresarial y una depuración de la Guardia Nacional en sus elementos más corruptos y ligados a la represión popular. La correlación de fuerzas con que se arribó al triunfo sandinista bloqueó la viabilidad de la estrategia, pero buena parte de lo que se hizo y del modo en que se hizo

"Expresión atribuida a Carlos Coronel Kautz, inicialmente ministro del Instituto Nicaragüense de Pesca, posteriormente sumado a ARDE (Alianza Revolucionaria Democrática), grupo contrarrevolucionario dirigido por Edén Pastora que operaba desde Costa Rica, acogido en 1987 a la amnistía otorgada por el gobierno sandinista en el marco de los acuerdos de Esquipulas II, y hasta muy recientemente administrador de proyectos de reforma agraria del MIDINRA -de cuya dirección superior formaban parte sus hermanos Ricardo y Manuel. 


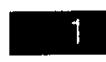

\section{4}

8

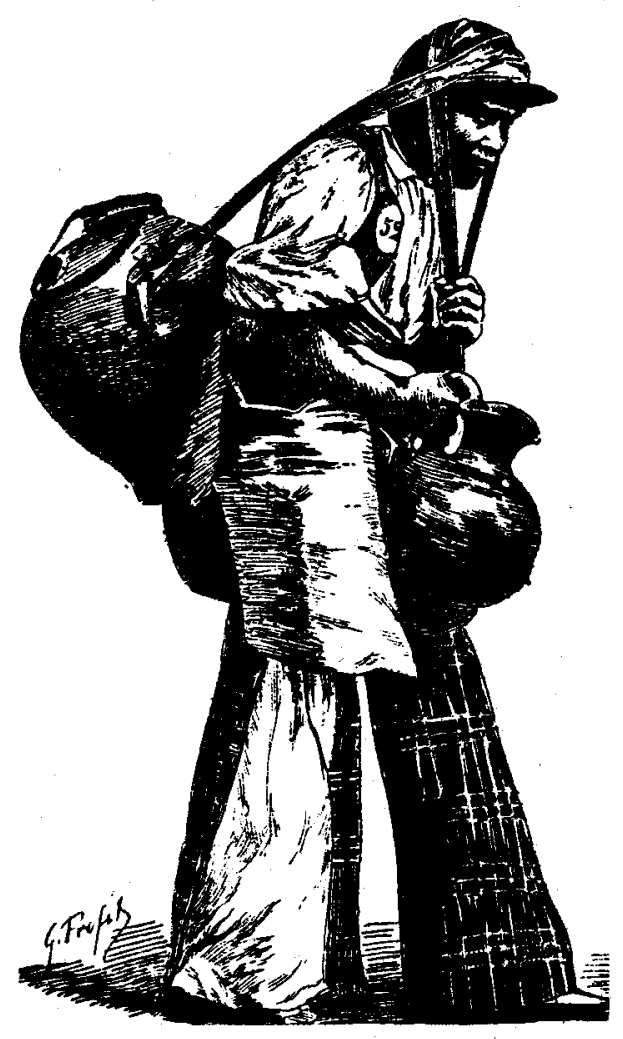

durante el segundo semestre de 1979 , se inscribe en este enfoque de confrontación limitada con el orden establecido y con el gobierno de Estados Unidos.

Once años después de aquel 19 de julio, Nicaragua tiene sin duda poco que ver con la sociedad imaginada por Carlos Fonseca y por los demás fundadores del FSLN, y por los que entonces y actualmente lo conducen. Pero no es tampoco la Nicaragua del 18 de julio. Es innegable el avance -que es muy anterior al 25 de febrero-de los usos y estilos de la cultura política tradicional, que tiñen de manera creciente todo el espectro de la política nacional, tanto en la UNO como en el FSLN. Pero al mismo tiempo las transformaciones introduci- das y experimentadas no son despreciables y han cambiado mucho más que la mera fachada del país. $Y$ aunque tras el 25 de febrero las perspectivas de un "somocismo sin Somoza" o de un "somocismo científico" parecen más firmes, los obstáculos que emergen de la sociedad y de sus actores mayoritarios, son hoy mucho más sólidos, aunque menos estrepitosos.

A pesar de las restricciones que trató de imponerles el estado en aras de la concertación con los grupos empresariales, los trabajadores cuentan hoy con una conciencia y una práctica de los derechos laborales inexistentes hace diez años; el acceso a los recursos básicos, tierra en primer lugar, es de una amplitud incomparable al de antes de la revolución, y si bien no es irreversible, el costo político y social de una contrarreforma agraria sería mayor que el que el gobierno de la UNO podría aceptar; las comunidades étnicas de la costa atlántica han avanzado un trecho importantísimo en el establecimiento de regímenes autónomos de gobierno. Una década de sandinismo ha desarrollado un sentido de eficacia política de la participación popular que constituye uno de los activos más importantes de este periodo. Esa participación no fue una dádiva del estado revolucionario, sino que la gente la ganó luchando contra el somocismo, contra los grupos dominantes integrados a la revolución, y a veces también contra los aparatos del propio estado revolucionario.

Las revoluciones cuando son auténticas, y la revolución sandinista lo fue, signan de manera indeleble todas las dimensiones de la sociedad, y aunque no triunfen, o sufran reveses, nada vuelve a ser lo que era antes. A pesar de las pesadillas de los hoy vencidos, y de las fantasías de sus azorados vencedores. 